\title{
Central CRF neurons are not created equal: phenotypic differences in CRF-containing neurons of the rat paraventricular hypothalamus and the bed nucleus of the stria terminalis
}

\author{
Joanna Dabrowska, Rimi Hazra, Ji-Dong Guo, Sarah DeWitt and Donald G. Rainnie* \\ Division of Behavioral Neuroscience and Psychiatric Disorders, Department of Psychiatry and Behavioral Sciences, Yerkes National Primate Research Center, \\ Emory University, Atlanta, GA, USA
}

Edited by:

James A. Carr, Texas Tech

University, USA

\section{Reviewed by:}

Gustavo M. Somoza, Instituto

de Investigaciones

Biotecnologicas-Instituto

Tecnologico de Chascomus,

Argentina

Michiru Hirasawa, Memorial

University, Canada

*Correspondence:

Donald G. Rainnie, Yerkes National

Primate Research Center, Emory

University, 954 Gatewood Rd.,

Atlanta, GA 30329, USA

e-mail:drainni@emory.edu
Corticotrophin-releasing factor (CRF) plays a key role in initiating many of the endocrine, autonomic, and behavioral responses to stress. CRF-containing neurons of the paraventricular nucleus of the hypothalamus (PVN) are classically involved in regulating endocrine function through activation of the stress axis. However, CRF is also thought to play a critical role in mediating anxiety-like responses to environmental stressors, and dysfunction of the CRF system in extra-hypothalamic brain regions, like the bed nucleus of stria terminalis (BNST), has been linked to the etiology of many psychiatric disorders including anxiety and depression. Thus, although CRF neurons of the PVN and BNST share a common neuropeptide phenotype, they may represent two functionally diverse neuronal populations. Here, we employed dual-immunofluorescence, single-cell RT-PCR, and electrophysiological techniques to further examine this question and report that CRF neurons of the PVN and BNST are fundamentally different such that PVN CRF neurons are glutamatergic, whereas BNST CRF neurons are GABAergic. Moreover, these two neuronal populations can be further distinguished based on their electrophysiological properties, their co-expression of peptide neurotransmitters such as oxytocin and arginine-vasopressin, and their cognate receptors. Our results suggest that CRF neurons in the PVN and the BNST would not only differ in their response to local neurotransmitter release, but also in their action on downstream target structures.

Keywords: CRF, BNST, PVN, Oxytocin, VGLUT2, GAD67, vasopressin

\section{INTRODUCTION}

Corticotrophin releasing factor (CRF) is a neuropeptide that is essential for coordinating the adaptive response of an organism to stressful situations (Vale et al., 1981). CRF is produced predominantly by neurons in the parvocellular division of the paraventricular nucleus of the hypothalamus (PVN) (Swanson et al., 1983; Herman et al., 2003). However, CRF is also produced by neurons in extra-hypothalamic limbic structures like the extended amygdala, which includes the bed nucleus of the stria terminalis (BNST) and the central nucleus of the amygdala (CeA), as well as in hindbrain structures like the locus coeruleus and dorsal Raphé nuclei (Cummings et al., 1983; Curtis and Valentino, 1994; Snyder et al., 2012). CRF that is synthesized and released by PVN neurons plays a major role in regulating activity of the hypothalamic-pituitary-adrenal (HPA) axis and triggers the classic endocrine stress response (Vale et al., 1981; Rivier and Vale, 1983), whereas outside the HPA axis CRF acts not as a hormone, but as a modulator of synaptic transmission at pre- and postsynaptic sites within specific central neuronal circuits (Lowry and Moore, 2006; Orozco-Cabal et al., 2006). In the BNST, the highest concentration of CRF neurons are found in the oval and fusiform nuclei (Cummings et al., 1983; Morin et al., 1999), which is also rich in CRF fibers and terminals, many of which originate from the CeA (Cummings et al., 1983; Sakanaka et al., 1986; Morin et al., 1999). Growing evidence suggests that CRF neurons of the anterolateral cell group of the $\mathrm{BNST}, \mathrm{BNST}_{\mathrm{ALG}}$, play a major role in the affective response to stressors (Lee and Davis, 1997; Liang et al., 2001; Nijsen et al., 2001; Ciccocioppo et al., 2003; Sahuque et al., 2006; Dabrowska et al., 2013), and that dysfunction of this CRF system contributes to the etiology of several psychiatric disorders, including depression (Crestani et al., 2010), anxiety-disorders (Walker et al., 2009), as well as addiction (Koob, 2010).

However, despite sharing a common neuropeptide phenotype, central CRF neurons should not be regarded as a homogeneous cell population. For example, the Raphé nuclei contain a population of CRF neurons that co-localize serotonin (5-HT) (Valentino et al., 2010), whereas locus coeruleus CRF neurons co-localize noradrenalin (NA) (Valentino et al., 1983, 2010). Hence, target structures that receive input from CRF neurons in these two midbrain nuclei would be predicted to have a markedly different response to afferent input. Consistent with this premise, evidence from in situ hybridization and immunohistochemical studies suggest that PVN CRF neurons could have a glutamatergic 
phenotype (Ziegler et al., 2002; Lin et al., 2003; Hrabovszky et al., 2005; Hrabovszky and Liposits, 2008), whereas BNST CRF neurons could be GABAergic (Sun and Cassell, 1993; Bowers et al., 1998; Day et al., 1999; Pompolo et al., 2002). This raises the intriguing possibility that either CRF neurons in these two stressreactive structures have a phenotype that is independent of the surrounding structure or that they co-express two functionally opposing neurotransmitters. Support for the latter premise comes from the observation that stress responsive neurons in the BNST, but not the PVN, are primarily GABAergic (Herman et al., 1996; Day et al., 1999; Bali et al., 2005; Janitzky et al., 2009). However, no study to date has systematically examined the neurochemical phenotype of CRF neurons in these two regions at the single cell level.

As noted above, the PVN and BNST also contain subpopulations of neurons that express a wide variety of neuropeptides including, but not limited to, oxytocin (OT), arginine-vasopressin (AVP), neurotensin (NT), and enkephalin (ENK) (Sawchenko et al., 1984a,b; Lightman, 1993), some of which are co-expressed in the same cell populations. For example, although AVP is primarily produced by magnocellular PVN neurons, under stress conditions parvocellular CRF neurons in the PVN also cosynthesize AVP (Sawchenko et al., 1984a; Arima et al., 2001), suggesting that the neurochemical phenotype of these neurons can be dynamically regulated in response to environmental demands. Interestingly, CRF and OT are also reported to be co-expressed in a subset of PVN neurons (Sawchenko et al., 1984b), and our recent single-cell RT-PCR study confirmed that some magnocellular OT neurons in the PVN also co-express mRNA transcripts for CRF (Dabrowska et al., 2011). Together these data suggest that stress responsive CRF neurons may have a phenotype that is both region-specific and dynamically regulated in response to environmental stimuli.

Finally, we recently reported that a reciprocal relationship exists between CRF neurons of the BNST $\mathrm{ALG}_{\mathrm{AL}}$ and OT neurons of the PVN (Dabrowska et al., 2011). Hence, magnocellular OT neurons in the PVN express high levels of type 2 CRF receptors (CRFR2), whereas BNST $\mathrm{ALG}_{\mathrm{AL}} \mathrm{CRF}$ neurons express high levels of OT receptor mRNA (OTR), suggesting that OT neurons of the PVN might directly regulate the excitability of the CRF neurons in the $\mathrm{BNST}_{\mathrm{ALG}}$ and vice versa. However, OT is also released locally in the PVN (Neumann, 2007), raising the possibility that CRF neurons in the PVN may also be regulated by local OT release. Indeed, we have shown that magnocellular CRF neurons in the PVN express OTR mRNA (Dabrowska et al., 2011), however, nothing is known about OTR expression in the parvocellular CRF cell population. Furthermore, although multiple neuronal subtypes have been characterized in the rat PVN (Tasker and Dudek, 1991) and BNST (Hammack et al., 2007; Hazra et al., 2011) based on their electrophysiological properties, litthe is known about the properties of CRF expressing neurons due to the lack of a cell-type specific marker for these neurons. To address these knowledge gaps, we have used a combination of dual-immunofluorescence and whole-cell patch clamp recording in conjunction with single-cell RT-PCR to probe rat CRF neurons in both regions for their expression of GABAergic (glutamic acid decarboxylase, GAD67) and glutamatergic (vesicular glutamate transporter, VGLUT) markers, as well as for other neuropeptides (OT, AVP) and their cognate receptors (OTR, V1AR, V1BR).

\section{METHODS}

\section{ANIMAL SUBJECTS}

All experiments were performed on brain tissue obtained from adult (60 days old), male, Sprague-Dawley rats (Charles River Laboratories, Wilmington, MA). Animals were housed 4 animals per cage and were maintained on a 12:12-h light-dark cycle with ad libitum access to food and water. For experiments that required stereotaxic surgery and colchicine injections, rats were anaesthetized with an IP injection of a mixture of dexdormitor $(0.16 \mathrm{mg} / \mathrm{kg}$; Pfizer Animal Health, New York, NY, USA) and ketamine hydrochloride $(48 \mathrm{mg} / \mathrm{kg}$; Butler-Schein Animal Health, Dublin, OH, USA). All procedures used were approved by the Institutional Animal Care and Use Committees (IACUC) of Emory University, and were in compliance with National Institutes of Health (NIH) guidelines for the care and use of laboratory animals.

\section{TISSUE PROCESSING FOR IMMUNOFLUORESCENCE}

To facilitate immunohistochemical analysis, 6 rats received a $2 \mu \mathrm{l}$ intracerebroventricular (icv) colchicine (Sigma Aldrich, St. Louis, MO, USA, $60 \mu \mathrm{g} / \mu \mathrm{l}$ ) infusion $48 \mathrm{~h}$ prior to transcardial perfusion to maximize CRF peptide content in neuronal cell bodies, as described previously (Dabrowska et al., 2011). Subsequently, all rats were transcardially perfused with $4 \%$ paraformaldehyde and subsequent fixation procedure was performed as described elsewhere (Dabrowska and Rainnie, 2010).

\section{DUAL-IMMUNOFLUORESCENCE EXPERIMENTS}

The specificity of the antibodies used in this study has been confirmed and described previously (Martin et al., 2010; Dabrowska et al., 2011). Dual-immunofluorescence experiments were performed using the following primary antibodies: rabbit polyclonal anti-CRF antibody (1:250, ab11133, Abcam, Cambridge, MA), mouse monoclonal anti-GAD67 (1:500, MAB5406, ChemiconMillipore, Billerica, MA), mouse monoclonal anti-VGLUT2 antibody (1:1000, clone N29/29, 75-067, UC Davis/NIH NeuroMab Facility, Davis, CA, USA, Antibodies Incorporated) and using protocols that have been described previously (Dabrowska et al., 2011).

To examine the co-localization of CRF with GAD67 and VGLUT2, we performed dual-immunofluorescence experiments on free-floating serial sections of the rat $\mathrm{BNST}_{\mathrm{ALG}}$ and PVN as described before (Dabrowska et al., 2011). Here, representative sections were taken from Bregma +0.22 to $-0.4 \mathrm{~mm}$ for the $\mathrm{BNST}_{\mathrm{ALG}}$, and from -1.6 to $-2.12 \mathrm{~mm}$ for PVN. The sections were rinsed $3 \times(10 \mathrm{~min}$ each) in phosphate buffer saline (PBS), permeabilized with $0.5 \%$ Triton-X 100 in PBS, and incubated for $48 \mathrm{~h}$ at $4{ }^{\circ} \mathrm{C}$ with the following primary antibodies pairs diluted in $0.5 \%$ Triton-X/PBS solution: CRF/GAD67 and CRF/VGLUT2. Sections were rinsed $3 \times(10$ min each $)$ in PBS and then incubated at room temperature for $2 \mathrm{~h}$ with Alexa-Fluor secondary antibodies specific for the primary antibody host: namely Alexa-Fluor 488 goat anti-mouse IgG and Alexa-Fluor 568 goat anti-rabbit 
IgG (1:500, Invitrogen, Carlsbad, CA, USA). Following incubation with secondary antibodies, sections were rinsed $3 \times$ in PBS and $1 \times$ in $0.05 \mathrm{M}$ phosphate buffer $(\mathrm{PB})$, mounted on gelatincoated glass slides and coverslipped using mounting medium consisting of $12 \%$ mowiol (Sigma Aldrich, St. Louis, MO, USA) and $30 \%$ glycerol. Confocal spinning disk laser microscopy was used to analyze dual-immunofluorescence patterns and to obtain high-resolution photomicrographs using an Orca R2 cooled CCD camera (Hamamatsu, Bridgewater, NJ, USA) mounted on a Leica DM5500B microscope (Leica Mircosystems, Bannockburn, IL) equipped with a CSU10B Spinning Disk (Yokagawa Electronic Corporation, Tokyo, Japan). Analysis and semi-quantitative analysis of dual-labeled neurons in the PVN and the $\mathrm{BNST}_{\mathrm{ALG}}$ was performed with Simple PCI 6.6 software (Hamamatsu Corporation, Sewickley, PA, USA). For each pair of primary antibodies, immunoreactive neurons from representative sections containing either the $\mathrm{BNST}_{\mathrm{ALG}}$, or the PVN, (from three animals, thirty sections total) were counted and analyzed for dual-labeling. Co-localization was determined by capturing confocal Z-stack images and counting the number of neurons co-localizing the two markers (VGLUT2/CRF or GAD67/CRF) in all focal plans. Cell counts were then expressed as a percentage of the total number of neurons expressing CRF.

\section{SINGLE-CELL RT-PCR}

Single cell RT-PCR (scRT-PCR) protocols and the procedures used to determine mRNA transcript expression in single cells of the PVN and BNST $_{A L G}$ have been described in detail elsewhere (Dabrowska et al., 2011; Hazra et al., 2011). Briefly, following recording of the electrophysiological properties of neurons in each area, the cytoplasm was aspirated from recorded neurons into the patch recording pipette and then expelled into a microcentrifuge tube containing a reverse transcription (RT) cocktail (Applied Biosystems, Foster City, California). The RT product was then amplified in triplicate and screened for $18 \mathrm{~S}$ rRNA expression. Only those cells positive for $18 \mathrm{~S}$ rRNA were subjected to amplification with primers. Oligonucleotide primers used in the current study have been described elsewhere (Dabrowska et al., 2011; Hazra et al., 2011), with the exception of V1AR and V1BR, as well as VGLUT1 and VGLUT3. The primers used for V1 receptors were as follows: 5'-CGACACAGCAAGGGTGACAAGG-3' and 5'-AGGAAGCCA G CAACGCCG-3' (accession number NM_053019.2, 265 bp) for V1AR, and 5'-AGCATCAGTACCATCTCCAGG-3' and $5^{\prime}$ TGGTCTCCATAGTGGCTTCC-3' (NM_017205.2, 463 bp) for V1BR. The primers used for VGLUT were as follows: $5^{\prime}$-ACCC ATCGGAGGCCAGATCG-3' and $5^{\prime}$-GCCACTCCTCCCGC GT CTTGTGC-3' (NM_053859, 416 bp) for VGLUT1 and 5'-GGAA TCATTGACC AAGATGAGTTAGCTGA-3'and 5'-TTT AGGT GTTTCTGAGAAGT CTCCTTCGG-3' (AY117026, 200 bp) for VGLUT3.

\section{CONTROLS FOR THE SCRT-PCR}

PCR conditions were optimized using total RNA isolated from rat $\mathrm{BNST}_{\mathrm{ALG}}$ so that a PCR product could be detected from (250 pg $-1 \mathrm{ng}$ ) of total RNA without contamination caused by non-specific amplification. For each PCR amplification, sterile water was used instead of cDNA as a control for contaminating artifacts. A second negative control was performed in which the RT enzyme was excluded from the initial reaction mixture for each amplification reaction. All of the control tests gave negative results throughout the study. In addition, all of the primers used in this study were intron-spanning to exclude amplification of genomic DNA. Moreover, the cell nucleus was never harvested while isolating mRNA from single cells further reducing the possibility of contamination by genomic DNA.

\section{IN VITRO WHOLE CELL PATCH-CLAMP RECORDING OF VISUALLY IDENTIFIED NEURONS IN THE PVN AND THE BNST ALG}

In vitro patch-clamp recordings were performed as previously described (Guo and Rainnie, 2010; Hazra et al., 2011). In brief, rat were anesthetized using isoflurane and the brains rapidly removed and placed into ice-cold kynurenic-based artificial cerebrospinal fluid ( $\mathrm{ACSF}_{\mathrm{KA}}$ ), which contained (in $\mathrm{mM}$ ): $\mathrm{NaCl}(130)$, $\mathrm{KCl}$ (3.5), $\mathrm{KH}_{2} \mathrm{PO}_{4}$ (1.1), $\mathrm{MgCl}_{2}$ (6.0), $\mathrm{CaCl}_{2}$ (1.0), $\mathrm{NaHCO}_{3}$ (30), glucose (10), and kynurenic acid (2). Subsequently, $350 \mu \mathrm{m}$ slices containing the $\mathrm{BNST}_{\mathrm{ALG}}$ or $\mathrm{PVN}$ were obtained using a Leica VTS-1000 vibrating microtome (Leica Microsystems, Bannockburn, IL). ACSF KA $_{\text {was }}$ used to minimize any potential excitotoxicity associated with glutamate release during tissue slicing. Immediately after slicing, slices were hemisected, trimmed, and placed in a holding chamber containing oxygenated ACSF KA at room temperature for $1 \mathrm{~h}$. Slices were then transferred to oxygenated regular ACSF containing (in $\mathrm{mM}$ ): $\mathrm{NaCl}$ (130), $\mathrm{NaHCO} 3$ (30), $\mathrm{KCl}$ (3.50), $\mathrm{KH} 2 \mathrm{PO} 4$ (1.10), $\mathrm{MgCl} 2$ (1.30), $\mathrm{CaCl} 2$ (2.50), and glucose (10). Slices were kept in the regular ACSF at room temperature for at least $30 \mathrm{~min}$ before recording. For recording, individual slices were transferred to a Warner Series 20 recording chamber $(0.5 \mathrm{ml}$ volume $)$ mounted on the fixed stage of a Leica DM-LFS microscope (Leica Microsystems). The slices were maintained fully submerged and continuously perfused with ACSF heated to $32^{\circ} \mathrm{C}$, and gassed with a $95-5 \%$ oxygen/carbon dioxide mixture. Neurons were visually identified using differential interference contrast (DIC) optics, infrared (IR) illumination, and an IR sensitive CCD camera (Orca ER, Hamamatsu, Tokyo Japan).

Standard whole-cell recordings in current- and voltage-clamp mode were obtained from $\mathrm{BNST}_{\mathrm{ALG}}$ and $\mathrm{PVN}$ neurons using a MultiClamp 700B amplifier (Molecular Devices, Sunnyvale, CA), with a Digidata 1320 A A-D interface, and pClamp 10 software (Molecular Devices). Current-clamp signals were filtered at $5 \mathrm{kHz}$ and digitized at $10-20 \mathrm{KHz}$. Patch pipettes were fabricated from borosilicate glass (resistance 4-7 M $\Omega$ ) and filled with a recording solution of the following composition (in $\mathrm{mM}$ ): $130 \mathrm{~K}$-gluconate, $2 \mathrm{KCl}, 10 \mathrm{HEPES}, 3 \mathrm{MgCl}_{2}$, and 5 phosphocreatine, $2 \mathrm{~K}$-ATP, 0.2 NaGTP.

For all experiments, whole-cell patch-clamp configuration was established only when the seal resistance was $>1.5$ G $\Omega$. Neurons were excluded from analysis if they showed a resting membrane potential $(\mathrm{Vm})$ more positive than $-50 \mathrm{mV}$ and/or had an action potential that did not overshoot $+10 \mathrm{mV}$. Series resistance (Rs) was bridge balanced and neurons with Rs $>25 \mathrm{M} \Omega$ were not included in analysis. Standardized protocols were used to determine the membrane properties of PVN and BNST neurons as previously described (Hammack et al., 2007). Briefly, 
the voltage response of neurons was determined using transient (750 ms) outward and inward current steps of 10-50 pA based on membrane input resistance $(\mathrm{Rm})$ of neurons, with the maximum hyperpolarizing voltage deflection restricted to $\sim-90 \mathrm{mV}$. Action potential properties were determined using an inward ramp of current $(250 \mathrm{~ms})$ sufficient to drive a single action potential. All electrophysiological data were analyzed with a custom made MATLAB 2009a script (Mathwork, Natick, MA). In a subpopulation of PVN neurons, $0.3 \%$ biocytin was included in the patch recording solution for morphological reconstructions as previously described (Hazra et al., 2011). PVNpc and PVNmc cells were distinguished from one another based on their relative medial / lateral location in the PVN, as well as by the apparent size of their soma (PVNpc $=10.7 \pm 0.5 \mu \mathrm{m}, n=18$; PVNmc $=$ $18.8 \pm 0.8 \mu \mathrm{m}, n=18)$.

\section{STATISTICAL ANALYSIS}

Statistical analyses were carried out using Prism 4 (GraphPad, La Jolla, CA). Tests for significant effect of cell type were performed using one way analysis of variance (ANOVA). To perform pairwise comparisons following significant main effects in ANOVA, Bonferroni multiple comparisons test were used. A $t$-test was used when only two cell types (PVNpc and PVNmc) were being compared. For all tests, significance was defined at $\alpha=0.05$.

\section{RESULTS}

\section{DUAL-IMMUNOFLUORESCENCE}

\section{GAD67 and VGLUT2 expression in the PVN}

To determine the predominant amino-acid neurotransmitter phenotype of CRF neurons in the PVN and BNST $_{\mathrm{ALG}}$, we performed dual-immunofluorescence for CRF together with specific markers for glutamatergic and GABAergic neurons. We chose GAD67 as the marker of GABAergic neurons because previous studies had shown a high levels of GAD67 mRNA expression in the BNST (Pompolo et al., 2002). Similarly, although three different isoforms of VGLUT are found in the CNS (Ziegler et al., 2002; Herzog et al., 2004), VGLUT2 is the predominant glutamate transporter found in the PVN (Hrabovszky et al., 2005). Hence, we conducted dual-immunofluorescence studies to examine the relative degree of co-expression of CRF with GAD67 or VGLUT2 in the PVN and the BNST $_{\mathrm{ALG}}$.

As expected, CRF-immunoreactivity in the PVN was mainly localized in a subpopulation of parvocellular neurons in the medial parvocellular division and, to a lesser extent, in a subpopulation of magnocellular neurons (Figures 1A-C). In contrast, GAD67-immunoreactivity showed high somatodendritic expression in the perinuclear division of the PVN and low expression in either the parvocellular or magnocellular subdivisions (Figure 1B'). Dual-immunofluorescence experiments demonstrated that CRF- and GAD67-immunoreactive neurons exist mainly in adjacent, but mutually exclusive, neuronal subpopulations in the hypothalamus, and only $13 \%(16 / 124)$ of CRF neurons in the PVN co-localize GAD67 (Figure 1B"). Conversely, VGLUT2-immunoreactivity showed high somatodendritic labeling throughout the PVN (Figure 1C') and our dual-immunofluorescence experiments revealed that the great majority $(82 \%, 67 / 82)$ of CRF-positive neurons in the PVN also co-localized VGLUT2 (Figure 1C”). However, numerous VGLUT2 positive neurons were also observed in the PVN that did not co-localize CRF.

\section{GAD67 and VGLUT2 expression in the BNST $T_{A L G}$}

In agreement with previous studies, CRF-immunoreactive neurons were concentrated in the oval and fusiform nuclei of the BNST, which also showed a dense network of CRF-positive fibers (Figures 2A-C). Consistent with previous in situ studies (Day et al., 1999; Pompolo et al., 2002), a high level of GAD67 somatodendritic immunoreactivity was observed throughout the BNST $_{\text {ALG }}$ (Figure 2B'), and dual-immunofluorescence experiments further revealed that 95\% (61/64) of CRF-positive neurons in the oval nucleus co-localized GAD67 (Figure 2B"). However, the majority of GAD67-positive neurons in the BNST $_{\text {ALG }}$ do not co-localize CRF. Unlike GAD67, VGLUT2 immunoreactivity in the oval nucleus of the $\mathrm{BNST}_{\mathrm{ALG}}$ was low, and restricted mainly to the neuropil where it presented as more punctuate-like labeling rather than the somatodendritic labeling of GAD67 (Figure 2C'). Furthermore, unlike GAD67, a somatic co-expression of VGLUT2 in $\mathrm{CRF}$-positive neurons of the $\mathrm{BNST}_{\mathrm{ALG}}$ was never observed (Figure 2C”).

Having determined that CRF neurons of the oval nucleus of the BNST $_{\mathrm{ALG}}$ and PVN could be differentiated based on their amino acid neurotransmitter phenotype, we were interested to see if they could be further differentiated based on their relative expression of other neuropeptides and their cognate receptors. Technical constraints limit the number of epitopes that can be labeled by antibodies in a single neuron and, hence, we next used a combination of whole-cell patch-clamp recording and singlecell RT-PCR to screen physiologically identified neurons in the parvocellular and magnocellular divisions of the PVN (PVNpc and PVNmc, respectively), and $\mathrm{BNST}_{\mathrm{ALG}}$ for their expression of mRNA transcripts for multiple peptide neurotransmitters and their receptors.

\section{SINGLE-CELL RT-PCR}

Having visually identified putative PVNmc and PVNpc neurons, and $\mathrm{BNST}_{\mathrm{ALG}}$ neurons, we first recorded their basic electrophysiological properties (see below) and then extracted cytosolic mRNA (see Methods). Figures 3A-C shows representative photomicrographs of putative magnocellular and parvocellular neurons in the PVN. In a subpopulation of neurons biocytin was included in the recording pipette to allow subsequent morphological reconstruction of the PVN neurons. Typical examples of a putative PVNmc (right) and PVNpc neuron (left) in the medial dorsal PVN are shown in Figure 3D. The combined results of our scRT-PCR analysis of mRNA transcripts obtain from neurons in the two divisions of the PVN and $\mathrm{BNST}_{\mathrm{ALG}}$ are summarized below and in Tables 1,3 . The physiological properties of $\mathrm{BNST}_{\mathrm{ALG}}$ and PVN neurons that express CRF transcripts are described briefly in the following section, and summarized in Table 2.

\section{Expression of mRNA transcripts in PVN neurons}

Single-cell RT-PCR analysis was performed on mRNA isolated from 43 PVN neurons, of which 21 were putative PVNpc 

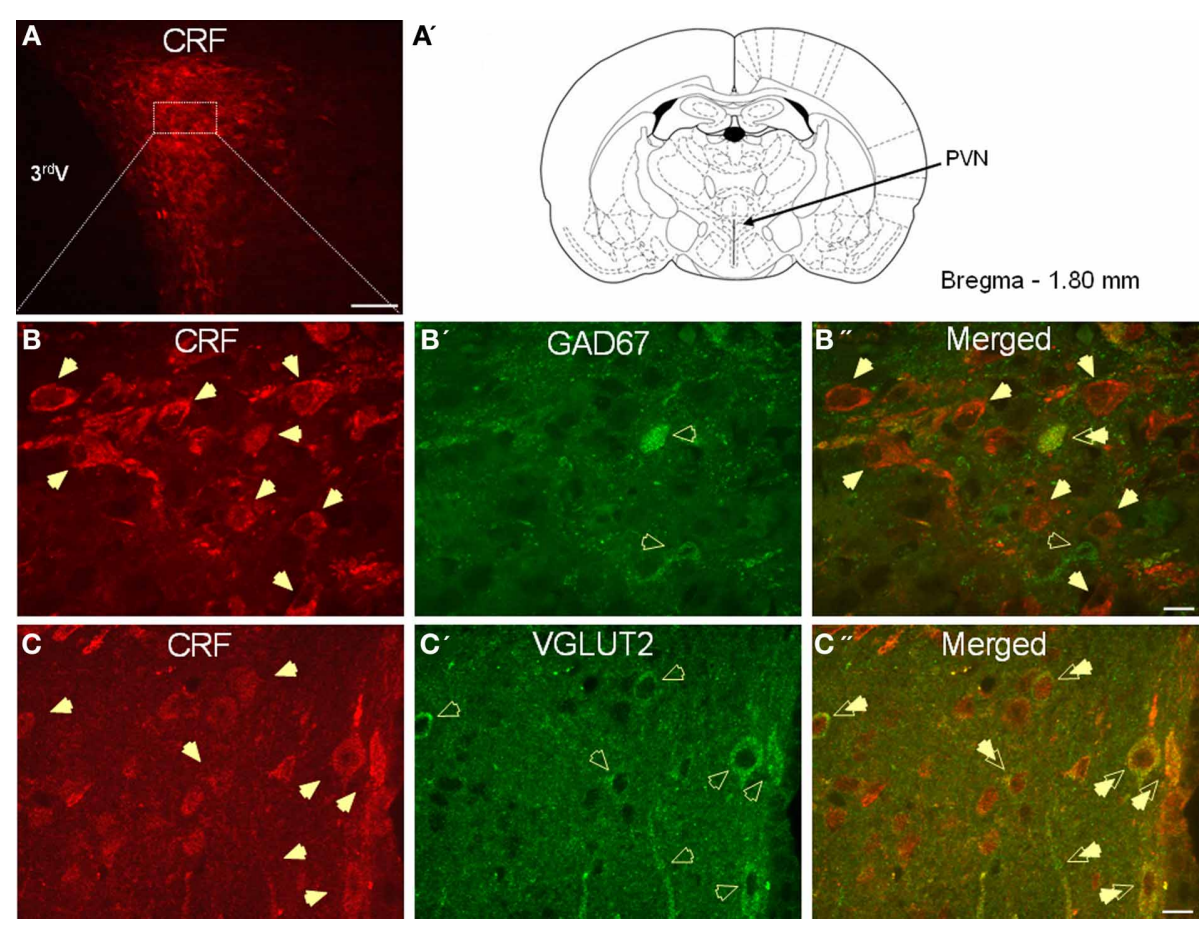

FIGURE 1 | (A) Photomicrograph showing high somatodendritic immunoreactivity of CRF in the parvocellular neurons of the PVN (magnification 10x, scale bar $10 \mu$, 3rd V-third ventricle). (B-B"): Photomicrographs showing non-overlapping somatodendritic immunoreactivity of CRF (B, red, closed arrows) and GAD67 (B', green, open arrows) in the PVN (B", merged). Occasionally, CRF-positive cells demonstrate immunolabeling for GAD67 as indicated by double arrow. (C-C") In contrast, CRF-immunoreactive neurons (B, red) are highly co-localized with

VGLUT2-positive neurons (B', green) in the parvocellular PVN (merged arrows, magnification $63 \times$, scale bar $10 \mu \mathrm{m}$ ). neurons, and 22 were putative PVNmc neurons. Previously, we have briefly described the genetic phenotype of a sample population of magnocellular PVN neurons (Dabrowska et al., 2011). Here, we extend these studies to include a more detailed examination of the phenotype of PVNpc and PVNmc neurons.

To verify the results from our immunohistochemical studies, all neurons were initially screened for the presence of mRNA transcripts for GAD67, as well as VGLUT1, VGLUT2, and VGLUT3. As expected, 86\% (37/43 neurons) of PVN neurons screened in this study expressed mRNA transcripts for VGLUT2, and none expressed GAD67 transcripts, further confirming that PVN neurons have a predominantly glutamatergic phenotype. Moreover, consistent with results from previous in situ hybridization studies (Ziegler et al., 2002; Herzog et al., 2004; Singru et al., 2012), none of the PVN neurons screened expressed mRNA transcripts for either VGLUT1 or VGLUT3 (data not shown), suggesting that VGLUT2 is a unique identifier for glutamatergic neurons of the PVN. Having established that PVN neurons were predominantly glutamatergic we next examined the relative extent of coexpression of CRF mRNA transcripts with VGLUT2 transcripts. In $21 \mathrm{PVNpc}$ neurons screened, 62\% (13/21) expressed mRNA transcripts for CRF. Consistent with our immunohistochemical data, 92\% (12/13) of PVNpc neurons that expressed CRF mRNA transcripts also expressed VGLUT2, and none expressed GAD67 transcripts.
Next, we examined the relative extent of co-expression of CRF transcripts in PVNpc neurons with transcripts for OT, AVP, and ENK, together with the cognate receptors for OT and AVP. As illustrated in Table 1, 77\% of parvocellular CRFpositive neurons (10/13) were seen to co-express mRNA transcripts for OT and V1BR, 54\% for CRFR2 (7/13), and only $8 \%$ expressed transcripts for ENK (1/13). None of the parvocellular CRF neurons examined in this study expressed transcripts for CRFR1, AVP, OTR, or V1AR mRNA. In contrast, 75\% of nonCRF parvocellular neurons expressed ENK and OTR (6/8), 62\% expressed VGLUT2 and CRFR2 (5/8), 37\% expressed transcripts for AVP (3/8), and only $25 \%$ expressed transcripts for OT and $\operatorname{V1BR}(2 / 8)$.

We have previously briefly described the expression phenotype of a sample population of magnocellular CRF-positive neurons (Dabrowska et al., 2011). Here we extend these observations and compare their expression phenotype with that of parvocellular CRF neurons. Out of $22 \mathrm{PVNm}$ neurons screened in this study, only four expressed the mRNA for CRF. Like parvocellular CRF neurons, 75\% of magnocellular CRF neurons (3/4) expressed mRNA transcripts for OT, CRFR2, and V1BR, 50\% expressed transcripts for VGLUT2 (2/4), and 25\% expressed transcripts for AVP and ENK (1/4). Interestingly, whereas no parvocellular CRF neurons expressed transcripts for OTR, 50\% of magnocellular CRF neurons showed OTR expression. Finally, V1BR transcripts were preferentially expressed 

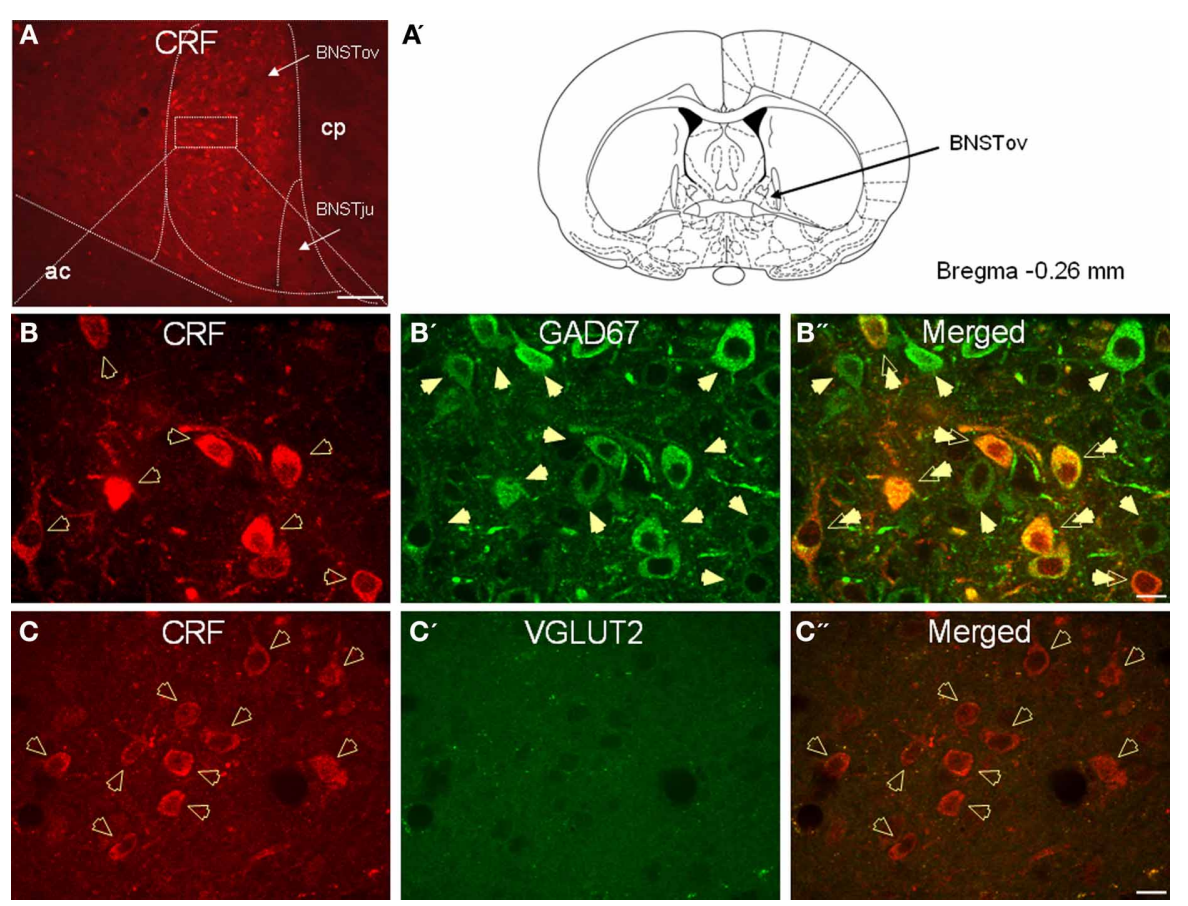

FIGURE 2 | (A) Photomicrograph showing high somatodendritic immunoreactivity of CRF in the BNST ALG (magnification 10x, scale bar $100 \mu$, ac, anterior commissure; $\mathrm{cp}$, caudate putamen; BNSTov, oval nucleus of the BNST; BNSTju, juxtacapsular nucleus of the BNST). (B-B"): Photomicrographs showing high-level co-localization of CRF (B, red) and GAD67 (B', green) in the
BNST $_{A L G}$ (B", merged, double arrows). Virtually all CRF-immunoreactive neurons co-express GAD67, but numerous GAD67-positive neurons do not co-localize CRF in the BNST $A L G$. (C-C") In contrast, CRF-immunoreactive neurons (B, red, open arrows) do not co-localize VGLUT2 (C', green) in the BNST $_{\text {ALG }}$ (magnification $63 \times$, scale bar $10 \mu \mathrm{m}$ ).

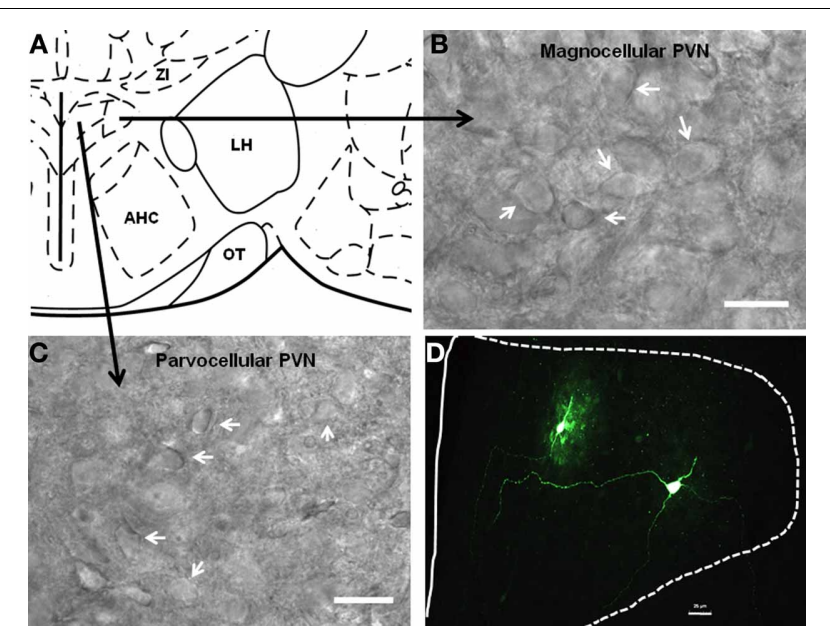

FIGURE 3 | Localization of parvocellular and magnocellular neurons in the PVN. (A) A schematic diagram showing the recording sites from the PVN neurons. (B,C) Representative images showing the cytoarchitecture of magnocellular and parvocellular neurons under DIC illumination. (D) Immunofluoroscence image showing two anatomically reconstructed PVN neurons, one parvocellular and one magnocellular. Scale bar $25 \mu \mathrm{m}$.

by CRF neurons and were never observed to co-express with AVP mRNA transcripts in either PVNpc or PVNmc, suggesting that V1BR does not serve as an autoreceptor in AVP neurons.

\section{Expression of mRNA transcripts in BNST ${ }_{A L G}$ neurons}

Previously, we have shown that three physiologically and genetically distinct subclasses of neurons are present in the $\mathrm{BNST}_{\mathrm{ALG}}$, Type I-III (Hammack et al., 2007; Hazra et al., 2011). Type III BNST $_{\mathrm{ALG}}$ neurons are putative CRF neurons, since the majority (95\%) of these neurons express mRNA transcripts for CRF, and display a unique ion channel expression pattern that correlates with their electrophysiological features (Hazra et al., 2011). To determine if CRF neurons of the BNST $_{\mathrm{ALG}}$ share a phenotype with parvocellular CRF neurons of the PVN we screened Type I-III BNST neurons for the presence of GAD67 and VGLUT1-3 transcripts. Significantly, all BNST $\mathrm{ALG}_{\mathrm{AL}}$ neurons tested, irrespective of cell type, expressed GAD67 mRNA transcripts, but none of these neurons expressed transcripts for VGLUT1-3. These findings confirmed our immunohistochemical observations that CRF neurons in the $\mathrm{BNST}_{\mathrm{ALG}}$ have a predominantly GABAergic phenotype.

Having established that CRF neurons of the PVN and BNST $_{\mathrm{ALG}}$ could be differentiated based on their amino-acid phenotype, we next examined whether additional differences could be found in their peptidergic phenotype. The results of this study are summarized in Table 1. Significantly, unlike parvocellular CRF neurons that showed $83 \%$ co-expression with OT mRNA transcripts, none of the Type III CRF neurons tested co-expressed OT. Conversely, whereas $95 \%$ of Type III neurons expressed transcripts for OTR (18/19), no parvocellular CRF neurons expressed OTR transcripts. Moreover, although 54\% 
Table 1 | Transcriptomic analysis of CRF, non-CRF PVN cells, and Type I-III BNST ALG $_{\text {neurons. }}$

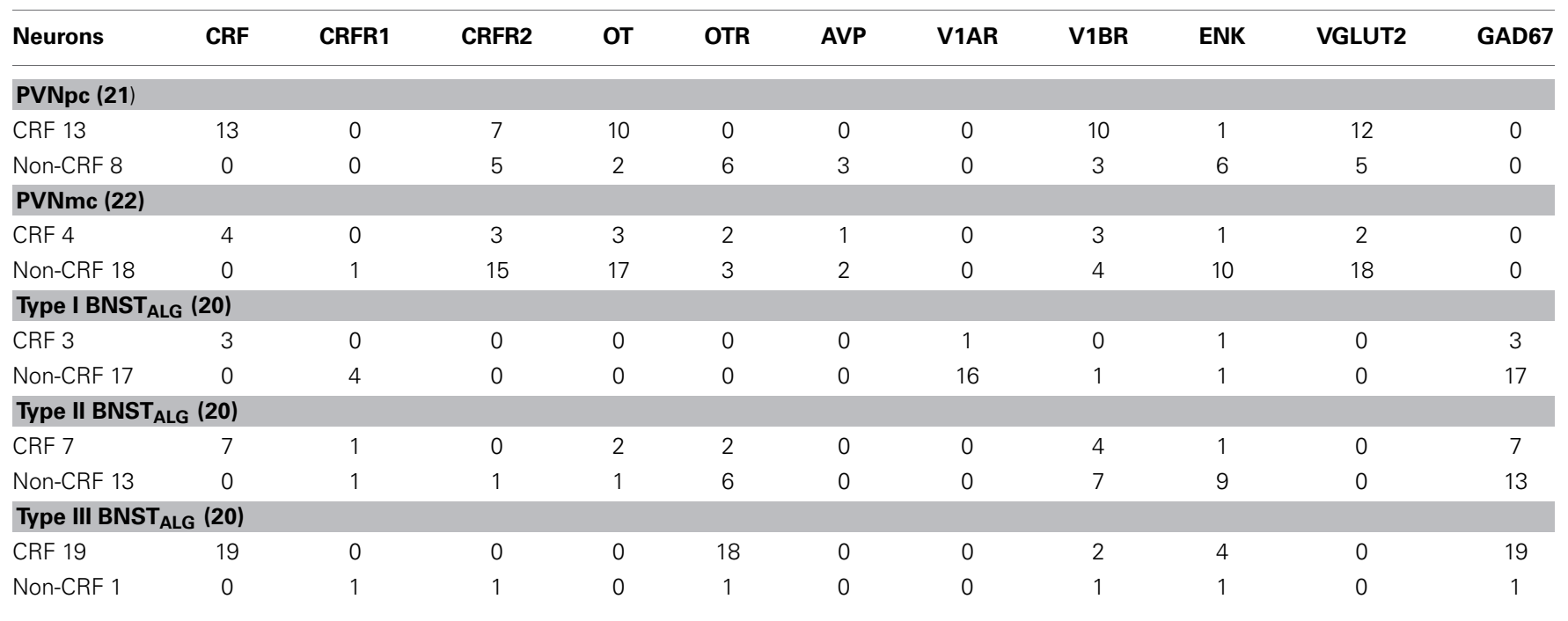

Table 2 | Distinct membrane properties of CRF neurons in the PVN and BNST ALG. $_{\text {. }}$

\begin{tabular}{|c|c|c|c|c|c|c|c|c|c|}
\hline CRF neurons & RMP (mV) & $\begin{array}{l}\text { 1st ISI } \\
\text { (ms) }\end{array}$ & $\operatorname{Rin}(m \Omega)$ & \multicolumn{6}{|c|}{ Spike } \\
\hline PVNpc (12) & $-56.3 \pm 0.94$ & $24.1 \pm 3.2$ & $1180 \pm 102$ & $70.1 \pm 2.4$ & $1.003 \pm 0.072$ & $-33.1 \pm 0.89$ & $0.36 \pm 0.022$ & $0.98 \pm 0.094$ & $-14.5 \pm 0.9$ \\
\hline PVNmc (4) & $-55.2 \pm 0.63$ & $19.0 \pm 3.3$ & $373 \pm 114 * *$ & $73.3 \pm 4.5$ & $1.01 \pm 0.042$ & $-33.2 \pm 1.12$ & $0.37 \pm 0.024$ & $0.89 \pm 0.030$ & $-19.2 \pm 2.6^{*}$ \\
\hline $\begin{array}{l}\text { Type III } \\
\text { BNST (19) }\end{array}$ & 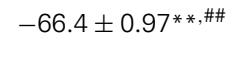 & $26.6 \pm 4.5$ & $226 \pm 17^{* *}$ & $76.9 \pm 1.4$ & $1.04 \pm 0.024$ & $-39.0 \pm 0.75^{*, \#}$ & $0.44 \pm 0.016$ & $1.12 \pm 0.045$ & $-4.9 \pm 0.5^{* *, \# \#}$ \\
\hline
\end{tabular}

${ }^{*, * *} p<0.05$ and 0.01 respectively, vs. PVNpc; \#,\#\# $p<0.05$ and 0.01 respectively, vs. PVNmc. ISI, inter-spike-interval; PVNpc, parvocellular neurons of the PVN; PVNmc, magnocellular neurons of the PVN.

of parvocellular CRF neurons expressed CRFR2 transcripts, no expression was observed in Type III CRF neurons and, finally only $10 \%$ of Type III CRF neurons expressed V1BR transcripts (2/19), whereas $77 \%$ of the parvocellular CRF neurons did. Hence, CRF neurons in the $\mathrm{BNST}_{\mathrm{ALG}}$ and the PVNpc would be expected to respond in distinctly different ways to local release of peptide neurotransmitters.

Examination of mRNA transcript expression for the different peptides and their receptors in Type I and Type II BNST $\mathrm{ALG}_{\mathrm{AL}}$

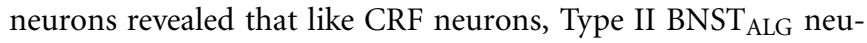
rons never express V1AR transcripts, whereas $94 \%$ of non-CRF Type I BNST neurons do. Interestingly, 36\% of those Type II neurons that co-expressed V1BR also expressed transcripts for CRF, similar to Type III neurons.

\section{ELECTROPHYSIOLOGICAL PROPERTIES OF PUTATIVE CRF NEURONS IN THE PVN AND BNST ALG}

Having determined that CRF neurons of the PVN and BNST $\mathrm{ALG}_{\mathrm{ALG}}$ have significantly different neurochemical phenotypes, we then examined whether the electrophysiological properties of these neurons was also different. The typical voltage response of CRF neurons in the PVNpc, PVNmc, and $\mathrm{BNST}_{\mathrm{ALG}}$ to transient (750 $\mathrm{ms}$ ) depolarizing and hyperpolarizing current injection is illustrated in Figure 4. As can be seen in Figures 4A,B (left upper traces), CRF neurons from both PVN regions displayed a similar voltage response to transient current injection. Hence, all neurons recorded from each region showed a moderate level of spike-frequency adaptation in response to $750 \mathrm{~ms}$ depolarizing current injections (PVNpc $n=12$, PVNmc $n=4)$. In contrast, $\mathrm{BNST}_{\mathrm{ALG}}$ CRF neurons exhibited a mixed firing pattern in response to depolarizing current injection. Like CRF neurons in

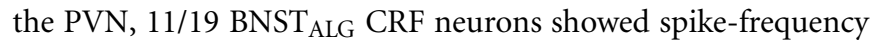
adaptation in the first $175 \pm 20 \mathrm{~ms}$, and then settled down to a regular firing pattern for the remainder of the pulse. The remaining 8/19 neurons showed no spike-frequency adaptation and fired regularly throughout the current injection protocol (Figure 4C). In response to hyperpolarizing current injection, voltage transients of neurons in each region showed a marked time-independent anomalous rectification. However, on closer examination one-way ANOVA tests found significant differences in resting membrane potential [RMP, $F_{(2,32)}=31.7, p<0.001$ ], input resistance [Rin, $\left.F_{(2,32)}=76, p<0.001\right]$, spike threshold $\left[F_{(2,32)}=13.7, p<0.001\right]$, and fast afterhyperpolarization [fAHP, $F_{(2,32)}=31.7, p<0.001$ ], as summarized in Table 2 . Post-hoc Bonferroni tests revealed that parvocellular CRF neurons had a significantly higher mean Rin than both the magnocellular 

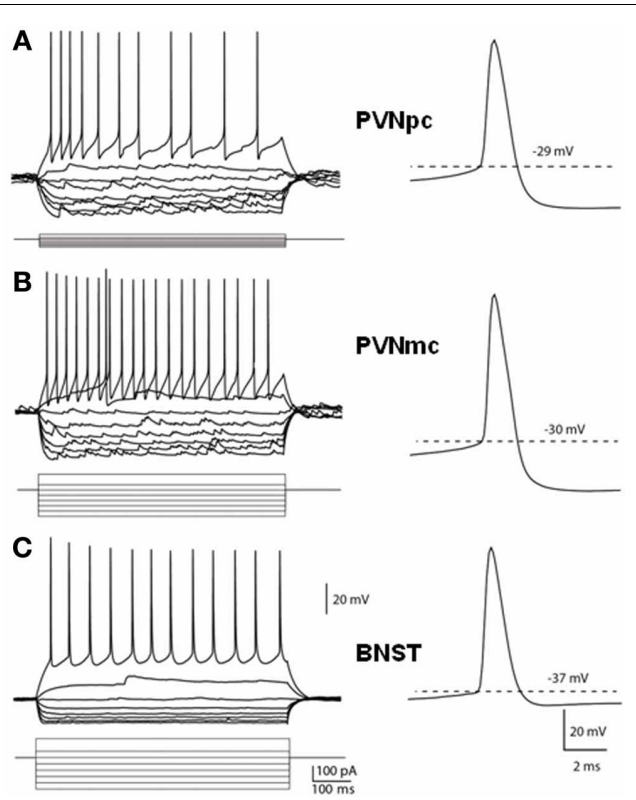

FIGURE 4 | Distinct membrane properties of putative CRF neurons in the PVN and type III CRF neurons in the BNST $_{\text {ALG. }}$. Representative traces demonstrate the membrane responses of these neurons to membrane current injections and typical spikes. (A) PVNpc neurons have extremely high input resistance and high threshold for spike firing. When hyperpolarized, these neurons exhibited an inward rectification current. No outward rectification was observed during depolarization current injections. Right trace shows a typical spike that has high firing threshold and a prominent fAHP. (B) PVNmc neurons have smaller input resistance than that of PNVpc neurons and also have high threshold for spike firing. Single spike trace also shows this neuron has a high spike threshold and prominent fAHP. (C) In comparison to the PVN CRF neurons, CRF neurons in the BNST have lower input resistances, lower spike threshold and smaller fAHP. PVNmc, PVNpc represent magnocellular and parvocellular neurons of PVN respectively.

Table 3 | Comparison of mRNA transcript expression of $\mathrm{I}_{\mathrm{T}}$ current channel subunits in PVN and BNST ${ }_{A L G}$ CRF neurons.

\begin{tabular}{lccc}
\hline CRF neurons & Cav3.1 & Cav3.2 & Cav3.3 \\
\hline PVNpc (13) & 10 & 6 & 0 \\
PVNmc (4) & 0 & 3 & 0 \\
Type III BNST ALG (19) & 0 & 0 & 16
\end{tabular}

CRF neurons, and BNST CRF neurons. On the other hand, both the parvo- and magnocelluar CRF neurons in the PVN exhibited a more pronounced fast after-hyperpolarizing potential (fAHP) following each spike, as well as a more depolarized resting membrane potential compared to that of $\mathrm{BNST}_{\mathrm{ALG}} \mathrm{CRF}$ neurons. Additionally, $\mathrm{CRF}$ neurons in the $\mathrm{BNST}_{\mathrm{ALG}}$ had a significantly more hyperpolarized threshold for action potential than both PVNpc and PVNmc neurons. The basic membrane properties of putative CRF neurons in the PVN and $\mathrm{BNST}_{\mathrm{ALG}}$ are summarized in Table 2.
Previous studies in the PVN had reported that expression of the low-threshold calcium current, $\mathrm{I}_{\mathrm{T}}$, was a unique identifier of parvocellular PVN neurons, which was markedly attenuated, or absent, in PVNmc neurons (Tasker and Dudek, 1991; Luther and Tasker, 2000), and that expression of this current may underlie differences in the firing patterns observed in these two regions. Similarly, we have shown that the firing pattern of BNST $_{\mathrm{ALG}}$ neurons is dependent on and interplay between $\mathrm{I}_{\mathrm{T}}$ and the transient outward potassium current, $\mathrm{I}_{\mathrm{A}}$ (Hammack et al., 2007). Hence, activation of $\mathrm{I}_{\mathrm{T}}$ may play a significant role in regulating the firing activity in CRF neurons in both the PVN and the BNST $\mathrm{ALG}_{\mathrm{AL}}$. As illustrated in Figure 4, CRF neurons in both the PVNpc and PVNmc failed to exhibit any of the rebound burst firing properties that were previously reported for type II neurons in the PVNpc (Luther and Tasker, 2000). However, burst firing was observed in a small population of non-CRF PVNpc neurons (data not shown). Alternatively, we reasoned that $\mathrm{I}_{\mathrm{T}}$ activation may influence the firing activity of PVNpc CRF neurons by regulating the inter-spike interval (ISI) between the first two spikes of a train of action potentials. Indeed, when looking at all of the PVNpc and PVNmc neurons, including those that do not express CRF, PVNpc neurons displayed a tendency toward a shorter 1st ISI in comparison to PVNmc neurons (26.8 \pm 4.7 vs. $42.5 \pm$ $11.2 \mathrm{~ms} ; p>0.05$ ), which may be indicative of more $\mathrm{I}_{\mathrm{T}}$ activation. However, no significant difference was observed for the $1 \mathrm{st}$ ISI in CRF PVNpc and PVNmc neurons (24.1 \pm 3.2 vs. $19.0 \pm$ $3.3 \mathrm{~ms}$, respectively), suggesting that CRF neurons in these two regions may share common properties that are distinct from nonCRF neurons. Although CRF neurons of the PVN and BNST $\mathrm{ALG}_{\mathrm{AL}}$ share many basic electrophysiological properties; Table 2 illustrates that $\mathrm{BNST}_{\mathrm{ALG}} \mathrm{CRF}$ neurons can be differentiated from their PVN counterparts in some of their basic membrane properties, which could significantly influence their response to excitatory afferent inputs. These data are consistent with our dual-immunofluorescence results, further suggesting that CRF neurons in the PVN and BNST represent distinct neuronal populations.

\section{EXPRESSION OF IT CHANNEL SUBUNITS IN CRF NEURONS OF THE PVN AND BNST $_{\text {ALG }}$}

To determine if the differences observed in the 1st ISI may be dependent on differential expression of $\mathrm{I}_{\mathrm{T}}$ channel subunits, we next examined the relative expression of mRNA transcripts for the $\mathrm{I}_{\mathrm{T}}$ channel subunits $\mathrm{Cav}_{3.1}, \mathrm{Cav}_{3.2}$, and $\mathrm{Cav}_{3.3}$ in CRF neurons of the PVN and BNST $\mathrm{ALG}_{\mathrm{AL}}$. As illustrated in Table 3, 54\% (7/13) of CRF-positive neurons in the PVNpc expressed mRNA transcripts for the $\mathrm{Cav}_{3.1}$ subunit, whereas only $38 \%$ (5/13) expressed transcripts for the Cav3.2 subunit. In contrast, the only $\mathrm{I}_{\mathrm{T}}$ channel subunit transcript expressed by PVNmc CRF neurons was the Cav3.2 subunit. Hence, 75\% (3/4) of PVNmc CRF neurons co-expressed $\mathrm{Cav}_{3.2}$ subunit transcripts. Significantly, the majority of non-CRF PVNmc neurons (15/22) failed to show mRNA transcript expression for any of the $\mathrm{I}_{\mathrm{T}}$ channel subunits (data not shown). In contrast to CRF neurons in the PVN, $85 \%$ of Type III CRF neurons in the BNST $_{A L G}$ expressed mRNA transcripts for the Cav3.3 subunit, but did not express transcripts for either Cav3.1 or Cav3.2 subunits. 


\section{DISCUSSION}

In this study we have demonstrated that CRF neurons in the PVNpc and in the $\mathrm{BNST}_{\mathrm{ALG}}$ display unique and regionally distinct expression patterns not only for the major amino acid neurotransmitters glutamate and GABA, but also for other neuropeptides and their receptors that are known to play a major role in the behavioral response to stress. Hence, our dualimmunofluorescence and scRT-PCR experiments revealed that PVNpc CRF neurons are predominantly glutamatergic, have the potential to synthesize and release oxytocin (OT), are unlikely to respond to local OT release, but could respond to local AVP and CRF release through activation of $\mathrm{V} 1 \mathrm{~B}$ and CRF2 receptors, respectively. Notably, PVNmc CRF neurons have a similar profile to that of PVNpc neurons. Conversely, Type III CRF neurons in the $\mathrm{BNST}_{\mathrm{ALG}}$ are predominantly GABAergic, do not have the ability to release OT or AVP, but could respond to local OT and AVP release via activation of OT and V1B receptors. Moreover, CRF neurons in the $\mathrm{BNST}_{\mathrm{ALG}}$ do not express CRF2 receptors and, hence, local CRF release would be predicted to differentially modulate the activity of CRF neurons in these two regions. Finally, our physiological data further suggests that excitatory afferents would be more likely to drive PVNpc CRF neurons to fire action potentials than they would CRF neurons of the $\mathrm{BNST}_{\mathrm{ALG}}$, even though the action potential threshold is lower in $\mathrm{BNST}_{\mathrm{ALG}}$ neurons, due to PVNpc neurons having a more depolarized resting membrane potential and higher input resistance.

Vesicular glutamate transporters are the main regulators of glutamate uptake into synaptic vesicles prior to its release from axon terminals (Fujiyama et al., 2001). To date three isoforms have been identified, VGLUT1-3, each of which show differential expression in the CNS (Ziegler et al., 2002; Herzog et al., 2004). Here we report that CRF neurons of the PVNpc and PVNmc exclusively express mRNA transcripts for VGLUT2, but not VGLUT1 or VGLUT3. The data is consistent with previous in situ hybridization and immunocytochemical studies showing that VGLUT2 is the predominant isoform expressed in the PVN (Ziegler et al., 2002), and that hypophysiotropic parvocellular CRF neurons of the PVN express VGLUT2 (Lin et al., 2003; Hrabovszky et al., 2005). Similarly, VGLUT2 has been reported to be the predominant glutamate transporter expressed by almost all hypothalamic neuroendocrine neurons, including CRF, thyrotropin releasing hormone (TRH; Herman et al., 2002; Hrabovszky and Liposits, 2008), OT, and AVP expressing neurons (Takamori et al., 2000; Herzog et al., 2001; Dabrowska et al., 2011), suggesting that glutamate may be the principal neurotransmitter released by these neurons under basal firing conditions. Unlike fast amino-acid synaptic transmission, release of peptide neurotransmitters is slow, requiring high frequency firing to elicit release, and is thought to modulate subsequent fast aminoacid transmission (Kits and Mansvelder, 2000; Greengard, 2001). Hence, transmission in efferent pathways from PVN CRF neurons may switch from solely glutamate, to glutamate and CRF during times of high PVN activation. Significantly, CRF has been shown to facilitate glutamatergic transmission in multiple brain regions (Liu et al., 2004; Rainnie et al., 2004; Hahn et al., 2009) but see (Gallagher et al., 2008), suggesting that concurrent activation of postsynaptic glutamate and CRF receptors may enhance HPA axis activity in response to chronic or intense stress stimuli.

Consistent with previous immunohistochemical studies (Cullinan et al., 2008) our scRT-PCR data confirm that neurons in the PVNmc (Dabrowska et al., 2011) and PVNpc do not express GAD67 mRNA transcripts. However, we have observed GAD67-immunoreactive neurons at high levels in the perinuclear region adjacent to the $\mathrm{PVN}$, which might be consistent with the presence of local inhibitory interneurons reported in earlier in situ hybridization studies of GAD67 expression in the PVN (Cole and Sawchenko, 2002). Indeed, CRF neurons of the medial PVNpc were shown to be targets of GABAergic inputs originating from neurons in the perinuclear zone (Roland and Sawchenko, 1993; Boudaba et al., 1996; Miklos and Kovacs, 2002), as well as from extrinsic sources such as the BNST (Herman and Cullinan, 1997).

The BNST is thought to be a major relay site for limbic input into the PVN (Cullinan et al., 1993; Dong et al., 2001; Zhu et al., 2001; Crane et al., 2003) and, notably, the PVNpc receives the heaviest BNST projection from the oval and fusiform nuclei, which contain the CRF neurons (Dong et al., 2001; Dong and Swanson, 2006). Lesion studies have shown that the anterior BNST mediates HPA axis activation, while the posterior BNST is involved in HPA axis inhibition (Choi et al., 2007) and therefore it has been suggested that CRF neurons of the anterior BNST might co-express glutamate (Silverman et al., 1989). However, we have shown that CRF neurons of the $\mathrm{BNST}_{\mathrm{ALG}}$ do not express mRNA transcripts for any of the three VGLUT isoforms and, instead, express transcripts and protein for GAD67. Our results are consistent with previous in situ hybridization studies showing that the BNST is predominantly a GABAergic structure (Sun and Cassell, 1993; Bowers et al., 1998; Day et al., 1999; Bali et al., 2005). At first glance these results would seem to contradict the results of the lesion studies showing activation of the HPA axis by the anterior BNST. However, Choi and colleagues proposed that it was the anterior BNST, ventral to the commissure, in the region of the fusiform nucleus that was responsible for activation

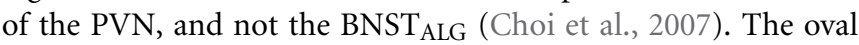
nucleus of the BNST $_{\mathrm{ALG}}$ projects heavily to the fusiform nucleus (Dong et al., 2001) and, hence, inhibition of fusiform neurons may functionally disinhibit the PVN.

More recently, it has been proposed that neurons in the region of the fusiform nucleus are glutamatergic (Georges and Aston-Jones, 2002; Jennings et al., 2013). However, there is some question about the validity this observation as the results from several in situ hybridization studies, including those reported in the Allen Brain Atlas, suggest that only a few putative VGLUT23 mRNA expressing neurons are present in this region (Herzog et al., 2001; Kudo et al., 2012). Nevertheless, if CRF neurons of the $\mathrm{BNST}_{\mathrm{ALG}}$ are involved in the acute response to stressors via an indirect pathway then inhibition of putative glutamatergic neurons in the ventral BNST would paradoxically decrease activation of the PVN. An alternative mechanism might be that activation of GABA/CRF neurons in the BNST $_{\mathrm{ALG}}$ could indirectly activate the HPA axis by dis-inhibiting GABAergic interneurons of the perinuclear zone. However, no study to date has reported direct projections from the $\mathrm{BNST}_{\mathrm{ALG}}$ to this region. 
Notably, Day and colleagues have suggested that systemic stressors, such as infection, do not activate CRF neurons in the $\mathrm{BNST}_{\mathrm{ALG}}$, but instead activate ENK neurons (Day et al., 1999) as measured by alterations in c-fos expression. However, Cullinan and colleagues (Cullinan et al., 1995) have reported that psychological stressors, such as restraint stress, cause a dramatic increase in the expression of another immediate early gene, Zif/268, but caused only low level c-fos expression. Hence, activation of CRF neurons on the $\mathrm{BNST}_{\mathrm{ALG}}$ may be critically dependent on the nature of the stressor, and detection of their activation is dependent on which immediate early gene is screened.

Interestingly, the majority of PVN CRF neurons also coexpressed mRNA transcripts for OT, and some of the magnocellular neurons also co-expressed transcripts for the OTR. OT is classically viewed as an anxiolytic neurotransmitter (Mccarthy et al., 1996; Ebner et al., 2005; Lee et al., 2009) and, hence, the potential for OT expression in parvocellular CRF neurons is intriguing and raises the possibility that these neurons could switch their neurochemical phenotype depending on environmental demands. Dynamic regulation of neuronal phenotype is not without precedence in the CNS. Hence, during lactation tuberoinfundibular dopamine neurons begin to express ENK, which prevents dopamine from inhibiting prolactin secretion (Merchenthaler, 1993). Dynamic changes in the expression of both CRF1 and CRF2 receptors were also reported in hypothalamic magnocellular neurons expressing AVP and OT in response to hyperosmotic stress (Arima and Aguilera, 2000). It is possible that prolonged periods of stress may dynamically regulate the neurochemical phenotype of parvocellular CRF neurons in a similar manner.

Moreover, our data showing co-expression of OT and OTR transcripts is consistent with previous autoradiography studies showing OTR expression in OT neurons (Adan et al., 1995), suggesting that the OTR in this cell population might serve as an autoreceptor to regulate OT release (Freund-Mercier and Richard, 1984). Interestingly, we reported previously that the majority of CRF neurons in the BNST $_{A L G}$ also expressed mRNA transcripts for the OTR (Dabrowska et al., 2011), suggesting that OT could regulate the activity of CRF neurons in the $\mathrm{BNST}_{\mathrm{ALG}}$ and therefore directly modulate affective behavior. In the current study we show that the majority of non-CRF neurons in the PVN have the potential to produce OTR, suggesting that local OT release could differentially modulate the excitability of the parvocellular neurons, and therefore impact the activity of the HPA axis as it was suggested before (Neumann et al., 2000). However, mRNA transcript expression does not necessarily translate into expression of the mature peptide, since we have previously demonstrated relatively sparse co-localization of CRF- and OT-neurons in the PVN (Dabrowska et al., 2011).

It is noteworthy that we saw no co-expression of CRF with AVP in either the PVN or BNST $_{\mathrm{ALG}}$, particularly considering that CRF and AVP have previously been reported to co-localize in both the PVNpc and PVNmc (Ma et al., 1997; Arima et al., 2001). Sawchenko and colleagues have reported that acute stress can cause a delayed induction of AVP mRNA transcripts in PVNpc CRF neurons (Kovacs and Sawchenko, 1993; Sawchenko et al., 1993). It is possible that in our unstressed animals the expression level of AVP transcripts is just below our detection threshold. In addition, is has been suggested that two populations of CRF neurons exist in the PVNpc, one that co-express AVP and one that does not (Whitnall and Gainer, 1988). It is possible that with our relatively small sample size we have unintentionally biased our recordings for scRT-PCR toward the former population.

We have also shown that Type III CRF neurons in the BNST ALG $_{\text {AL }}$ and PVNpc CRF neurons both express mRNA transcripts for V1BR, but not V1AR, whereas non-CRF Type I neurons of the BNST $_{A L G}$ express V1AR but not V1BR. These findings are consistent with previous studies showing a high level of expression of the $\mathrm{V} 1 \mathrm{~B}$ receptor in the PVN, where it is known to play an key role in modulating activity of the HPA axis (Nair and Young, 2006); for review see (Roper et al., 2011). Significantly, $\mathrm{V} 1 \mathrm{~B}$ receptor knockout mice have been shown to have a blunted ACTH response to both acute and repeated stress, however, this response is critically dependent on the context of the stressor (Lolait et al., 2007). Our results showing V1BR transcript expression in BNST $_{\mathrm{ALG}}$, as well as PVN, CRF neurons would suggest that the effect of the receptor knockout would depend on whether or not a particular stressor activated one or both of these pathways. Consistent with this hypothesis recent studies with the nonpeptide $\mathrm{V} 1 \mathrm{~B}$ receptor antagonist, suggest that extra-hypothalamic $\mathrm{V} 1 \mathrm{~B}$ receptors may play a critical role in the regulation of affect (Salome et al., 2006). We have preliminary scRT-PCR evidence suggesting that those Type I BNST ${ }_{A L G}$ neurons that express V1AR co-express GABA and either somatostatin or enkephalin (Hazra and Rainnie, unpublished observations). Hence, local AVP release might differentially regulate sub-populations of BNST $_{\mathrm{ALG}}$ neurons and modulate different behavioral outputs. Consistent with this notion, previous studies have suggested a complementary or cooperative effect of AVP receptor activation on behavioral output (Ring, 2005; Veenema and Neumann, 2008). Central V1B receptors were shown to mediate anxiety (Ishizuka et al., 2010), while V1A receptors in the BNST were positively correlated with maternal aggression (Bosch et al., 2010; Caughey et al., 2011). The BNST is known to mediate both anxiety-like and maternal aggression behavior, thus our results suggest that in the BNST, Type III CRF neurons and Type I neurons might mediate distinct anxietyand aggression-related behavioral outcomes, respectively.

Finally, using in vitro patch-clamp techniques, we have demonstrated that CRF neurons of the PVN and $\mathrm{BNST}_{\mathrm{ALG}}$ display similar, and yet distinct basic membrane properties. Previously, we have identified three electrophysiologically and genetically dis-

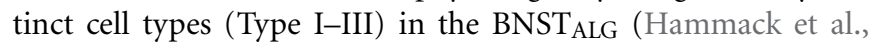
2007; Hazra et al., 2011), and have further identified Type III neurons as corresponding to the CRF containing cell population (Martin et al., 2010; Dabrowska et al., 2011). Previous studies in the PVN have also identified three neuronal subtypes (Type I-III) based on their electrophysiological properties (Hoffman et al., 1991; Tasker and Dudek, 1991; Luther and Tasker, 2000), and type I and II neurons were subsequently identified as being magnocellular and parvocellular neurons, respectively (Luther and Tasker, 2000). Significantly, the parvocellular CRF neurons recorded in our study have many electrophysiological properties similar to those previously reported for the neurosecretory subpopulation of type II parvocellular PVN neurons (Tasker and Dudek, 1991); 
in that PVNpc CRF neurons displayed moderate spike-frequency adaptation of the action potential firing pattern from rest, and had a pronounced post-spike fast AHP. However, no rebound low-threshold burst firing activity was observed in PVNpc CRF neurons following transient hyperpolarizing current injection. Two distinct cell populations have been reported in the PVNpc (Hermes et al., 1996), one of which shows robust rebound lowthreshold burst firing activity (type III) and one that does not (type II). Consistent with this observation we observed a subpopulation of non-CRF PVNpc neurons that did show low-threshold burst firing activity. Moreover, CRF PVNpc neurons showed a marked time-independent anomalous rectification of the voltage transient in response to hyperpolarizing current injection similar to that previously reported in type II and III PVNpc neurons.

Like the PVNpc CRF neurons, the PVNmc CRF neurons in this study also exhibited a marked time-independent anomalous rectification. However, PVNmc neurons have previously been reported to lack this time-independent inward rectification (Tasker and Dudek, 1991). Consistent with the previous studies, non-CRF PVNmc cells in the current study did not exhibit the inward rectification, indicating that the CRF PVNmc cells exhibit electrophysiological properties more similar to that of PVNpc neurons than other PVNmc neurons. Another distinguishing property of PVNmc, or Type I neurons, is a large A-type $\mathrm{K}^{+}$current $\left(\mathrm{I}_{\mathrm{A}}\right.$; Luther and Tasker, 2000). Although we did not measure $\mathrm{I}_{\mathrm{A}}$ directly in this study, we did observe an $\sim 200 \mathrm{~ms}$ delay in the onset to the first action potential in $3 / 4$ CRF PVNmc cells compared to PVNpc neurons in response to low intensity current injection (Figure 4B). However, due to the small sample size of PVNmc neurons $(n=4)$ it is impossible to draw any definitive conclusions about the factors mediating this response.

Intriguingly, CRF neurons of the PVN and $\mathrm{BNST}_{\mathrm{ALG}}$ had many overlapping physiological properties such as a regular firing pattern, and a strong inward-rectification of the voltage response to hyperpolarizing current injection. However, consistent with differences observed in our immunohistochemical and transcriptomic analysis, Type III CRF neurons and PVNpc CRF neurons were significantly different in many other aspects of their membrane properties. Hence, PVNpc CRF neurons had a much higher input resistance $(1180 \mathrm{M} \Omega)$ compared to the CRF neurons in the $\mathrm{BNST}_{\mathrm{ALG}}(226 \mathrm{M} \Omega)$, which suggests that the same excitatory input would cause a greater depolarization in PVNpc CRF neurons. Although CRF neurons in the $\mathrm{BNST}_{\mathrm{ALG}}$ had a more hyperpolarized threshold for action potential $(-39 \mathrm{mV})$ than PVNpc CRF neurons $(-33 \mathrm{mV})$, PVNpc CRF neurons also showed a more depolarized resting membrane potential $(-56 \mathrm{mV}) \mathrm{com}$ pared to BNST $_{\mathrm{ALG}} \mathrm{CRF}$ neurons $(-66 \mathrm{mV})$, which together with the higher input resistance suggests that excitatory synaptic input would be more likely to drive PVNpc CRF neurons to action potential threshold than those in the BNST $_{\mathrm{ALG}}$. Furthermore, previous studies have shown that PVNpc neurons exhibit a strong $\mathrm{I}_{\mathrm{T}}$ current that contributes to a low-threshold spiking pattern and only a little $\mathrm{I}_{\mathrm{A}}$ (Tasker and Dudek, 1991; Luther and Tasker, 2000). Although we did not observe burst firing in the current study, we have confirmed that the parvocellular PVN neurons, which expressed CRF, also co-expressed $\mathrm{Cav}_{3.1}$ and $\mathrm{Cav}_{3.2}$ subunits mediating the $\mathrm{I}_{\mathrm{T}}$ currents. Conversely, the Type III putative CRF neurons in the BNST do not exhibit low-threshold firing indicative of an $\mathrm{I}_{\mathrm{T}}$ current (Hammack et al., 2007), but do show significant $\mathrm{I}_{\mathrm{A}}$ currents (Rainnie et al., 2013). However, in the current study we have shown that the great majority of Type III,

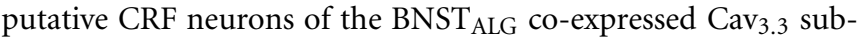
unit. The lack of low-threshold firing in these neurons, despite the probable presence of voltage-gated calcium channels, is most likely due to the opposing $\mathrm{I}_{\mathrm{A}}$ current found in these cells.

PVNpc CRF neurons are responsible for a rapid activation of the HPA axis to initiate the endocrine response to stress stimuli (Rivier and Vale, 1983), while the CRF neurons in the BNST $_{\mathrm{ALG}}$ are thought to modulate the affective component of the stress response, which is most likely context-dependent and slower (Walker et al., 2009) but see Sterrenburg et al. (2012). Thus, the functional separation of these two neuronal populations might be partially explained by their distinct membrane properties and concomitant ion channel expression pattern.

In conclusion, we reported that although CRF neurons in the PVN and the BNST $_{\text {ALG }}$ share the same neuropeptide phenotype, they represent distinct neuronal populations. Hypothalamic CRF neurons are glutamatergic (excitatory), whereas the CRF neurons in the $\mathrm{BNST}_{\mathrm{ALG}}$ are GABAergic (inhibitory). Functional separation of these two groups of CRF neurons can be further distinguished by their distinct membrane properties, such that hypothalamic CRF neurons are more likely to be rapidly activated in response to stress to initiate HPA axis activation, while CRF neurons in the $\mathrm{BNST}_{\mathrm{ALG}}$ display membrane properties which suggest that greater stimulus is needed to reach action potential threshold in these neurons. Consistent with this observation, CRF neurons in the BNST are thought to modulate the affective component of the stress response, and previous studies have suggested that in contrast to the PVN neurons, CRF neurons in the BNST may only be activated in response to chronic, but not acute stress (Kim et al., 2006). Furthermore, we have shown that OT and AVP as well as their cognate receptors co-exist in intimate relationships with CRF neurons in both PVN and the $\mathrm{BNST}_{\mathrm{ALG}}$. However, OT is more likely to regulate the excitability of CRF neurons in the BNST $_{\mathrm{ALG}}$ than in the PVN, therefore OT-CRF neurotransmission seems to be more likely involved in the affective component of the stress response than in the classic endocrine response to stress. In contrast, V1BR were widely expressed in both PVN and the BNST CRF neurons, which suggests that AVP may be involved in both HPA axis activation as well as in the affective component of the stress response, which is mediated by CRF neurons in the $\mathrm{BNST}_{\mathrm{ALG}}$.

\section{ACKNOWLEDGMENTS}

This work was supported by the National Institute of Mental Health grant (MH072908) to Donald G. Rainnie and by the National Center for Research Resources P51RR169, which is supported by the Office of Research Infrastructure Programs/OD P51OD11107. Joanna Dabrowska is supported by NIMH K99MH-096746 grant. 


\section{REFERENCES}

Adan, R. A., Van Leeuwen, F. W., Sonnemans, M. A., Hoffman, G., Verbalis, J. G., and Burbach, J. P. (1995). The rat oxytocin receptor. cDNA cloning and immunocytochemical localization in brain, pituitary, mammary gland and uterus. Adv. Exp. Med. Biol. 395, 345-346.

Arima, H., and Aguilera, G. (2000). Vasopressin and oxytocin neurones of hypothalamic supraoptic and paraventricular nuclei co-express mRNA for Type-1 and Type-2 corticotropin-releasing hormone receptors. J. Neuroendocrinol. 12, 833-842. doi: 10.1046/j.13652826.2000.00528.x

Arima, H., House, S. B., Gainer, H., and Aguilera, G. (2001). Direct stimulation of arginine vasopressin gene transcription by cAMP in parvocellular neurons of the paraventricular nucleus in organotypic cultures. Endocrinology 142, 5027-5030. doi: 10.1210/en.142.11.5027

Bali, B., Erdelyi, F., Szabo, G., and Kovacs, K. J. (2005). Visualization of stress-responsive inhibitory circuits in the GAD65-eGFP transgenic mice. Neurosci. Lett. 380, 60-65. doi: 10.1016/j.neulet.2005.01.014

Bosch, O. J., Pfortsch, J., Beiderbeck, D. I., Landgraf, R., and Neumann, I.D. (2010). Maternal behaviour is associated with vasopressin release in the medial preoptic area and bed nucleus of the stria terminalis in the rat. J. Neuroendocrinol. 22, 420-429. doi: 10.1111/j.13652826.2010.01984.x

Boudaba, C., Szabo, K., and Tasker, J. G. (1996). Physiological mapping of local inhibitory inputs to the hypothalamic paraventricular nucleus. J. Neurosci. 16, 7151-7160.

Bowers, G., Cullinan, W. E., and Herman, J. P. (1998). Regionspecific regulation of glutamic acid decarboxylase (GAD) mRNA expression in central stress circuits. J. Neurosci. 18, 5938-5947.

Caughey, S. D., Klampfl, S. M., Bishop, V. R., Pfoertsch, J., Neumann, I. D., Bosch, O. J., et al. (2011). Changes in the intensity of maternal aggression and central oxytocin and vasopressin vla receptors across the peripartum period in the rat. J. Neuroendocrinol. 23, 1113-1124. doi: 10.1111/j.1365-2826.2011.02224.x

Choi, D. C., Furay, A. R., Evanson, N. K., Ostrander, M. M., Ulrich-Lai, Y. M., and Herman, J. P. (2007). Bed nucleus of the stria terminalis subregions differentially regulate hypothalamic-pituitary-adrenal axis activity: implications for the integration of limbic inputs. J. Neurosci. 27, 2025-2034. doi: 10.1523/JNEUROSCI.4301-06.2007 Ciccocioppo, R., Fedeli, A., Economidou, D., Policani, F., Weiss, F., and Massi, M. (2003). The bed nucleus is a neuroanatomical substrate for the anorectic effect of corticotropin-releasing factor and for its reversal by nociceptin/orphanin FQ. J. Neurosci. 23, 9445-9451.

Cole, R. L., and Sawchenko, P. E. (2002). Neurotransmitter regulation of cellular activation and neuropeptide gene expression in the paraventricular nucleus of the hypothalamus. J. Neurosci. 22, 959-969.

Crane, J. W., Buller, K. M., and Day, T. A. (2003). Evidence that the bed nucleus of the stria terminalis contributes to the modulation of hypophysiotropic corticotropinreleasing factor cell responses to systemic interleukin-lbeta. J. Comp. Neurol. 467, 232-242. doi: 10.1002/cne.10918

Crestani, C. C., Alves, F. H., Correa, F. M., Guimaraes, F. S., and Joca, S. R. (2010). Acute reversible inactivation of the bed nucleus of stria terminalis induces antidepressant-like effect in the rat forced swimming test. Behav. Brain Funct. 6, 30. doi: 10.1186/1744-9081-6-30

Cullinan, W. E., Herman, J. P., Battaglia, D. F., Akil, H., and Watson, S. J. (1995). Pattern and time course of immediate early gene expression in rat brain following acute stress. Neuroscience 64, 477-505. doi: 10.1016/0306-4522(94)00355-9

Cullinan, W. E., Herman, J. P., and Watson, S. J. (1993). Ventral subicular interaction with the hypothalamic paraventricular nucleus: evidence for a relay in the bed nucleus of the stria terminalis. J. Comp. Neurol. 332, 1-20. doi: 10.1002/cne.903320102

Cullinan, W. E., Ziegler, D. R., and Herman, J. P. (2008). Functional role of local GABAergic influences on the HPA axis. Brain Struct. Funct. 213, 63-72. doi: 10.1007/s00429008-0192-2

Cummings, S., Elde, R., Ells, J., and Lindall, A. (1983). Corticotropinreleasing factor immunoreactivity is widely distributed within the central nervous system of the rat: an immunohistochemical study. J. Neurosci. 3, 1355-1368.

Curtis, A. L., and Valentino, R. J. (1994). Corticotropin-releasing factor neurotransmission in locus coeruleus: a possible site of antidepressant action. Brain
Res. Bull. 35, 581-587. doi: 10.1016/0361-9230(94)90172-4

Dabrowska, J., Hazra, R., Ahern, T. H., Guo, J. D., Mcdonald, A.

J., Mascagni, F., et al. (2011). Neuroanatomical evidence for reciprocal regulation of the corticotrophin-releasing factor and oxytocin systems in the hypothalamus and the bed nucleus of the stria terminalis of the rat: implications for balancing stress and affect. Psychoneuroendocrinology 36, 1312-1326. doi: 10.1016/j. psyneuen.2011.03.003

Dabrowska, J., Hazra, R., Guo, J.-D., Li, C., DeWitt, S., Xu, J., et al. (2013). Striatal-enriched protein tyrosine phosphatase - STEPs toward understanding chronic stress-induced activation of CRF neurons in the rat BNST. Biol. Psychiatry doi: 10.1016/ j.biopsych.2013.07.032

Dabrowska, J., and Rainnie, D. G. (2010). Expression and distribution of $\mathrm{Kv} 4$ potassium channel subunits and potassium channel interacting proteins in subpopulations of interneurons in the basolateral amygdala. Neuroscience 171, 721-733. doi: 10.1016/j.neuroscience.2010.09.011

Day, H. E., Curran, E. J., Watson, S. J. Jr., and Akil, H. (1999). Distinct neurochemical populations in the rat central nucleus of the amygdala and bed nucleus of the stria terminalis: evidence for their selective activation by interleukin1beta. J. Comp. Neurol. 413, 113-128.

Dong, H. W., Petrovich, G. D., Watts, A. G., and Swanson, L. W. (2001). Basic organization of projections from the oval and fusiform nuclei of the bed nuclei of the stria terminalis in adult rat brain. J. Comp. Neurol. 436, 430-455. doi: 10.1002/cne.1079

Dong, H. W., and Swanson, L. W. (2006). Projections from bed nuclei of the stria terminalis, anteromedial area: cerebral hemisphere integration of neuroendocrine, autonomic, and behavioral aspects of energy balance. J. Comp. Neurol. 494, 142-178. doi: 10.1002/cne.20788

Ebner, K., Bosch, O. J., Kromer, S. A., Singewald, N., and Neumann, I. D. (2005). Release of oxytocin in the rat central amygdala modulates stress-coping behavior and the release of excitatory amino acids. Neuropsychopharmacology 30, 223-230. doi: 10.1038/sj.npp.130 0607

Freund-Mercier, M. J., and Richard, P. (1984). Electrophysiological evidence for facilitatory control of oxytocin neurones by oxytocin during suckling in the rat. J. Physiol. 352, 447-466.

Fujiyama, F., Furuta, T., and Kaneko, T. (2001). Immunocytochemical localization of candidates for vesicular glutamate transporters in the rat cerebral cortex. J. Comp. Neurol. 435, 379-387. doi: 10.1002/cne.1037

Gallagher, J. P., Orozco-Cabal, L. F., Liu, J., and Shinnick-Gallagher, P. (2008). Synaptic physiology of central CRH system. Eur. J. Pharmacol. 583, 215-225. doi: 10.1016/j.ejphar.2007.11.075

Georges, F., and Aston-Jones, G. (2002). Activation of ventral tegmental area cells by the bed nucleus of the stria terminalis: a novel excitatory amino acid input to midbrain dopamine neurons. J. Neurosci. 22, 5173-5187.

Greengard, P. (2001). The neurobiology of slow synaptic transmission. Science 294, 1024-1030. doi: 10.1126/science.294.5544.1024

Guo, J. D., and Rainnie, D. G. (2010). Presynaptic 5-HT(1B) receptormediated serotonergic inhibition of glutamate transmission in the bed nucleus of the stria terminalis. Neuroscience 165, 1390-1401. doi: 10.1016/j.neuroscience.2009.11.071

Hahn, J., Hopf, F. W., and Bonci, A. (2009). Chronic cocaine enhances corticotropin-releasing factor-dependent potentiation of excitatory transmission in ventral tegmental area dopamine neurons. J. Neurosci. 29, 6535-6544. doi: 10.1523/JNEUROSCI.4773-08.2009

Hammack, S. E., Mania, I., and Rainnie, D.G. (2007). Differential expression of intrinsic membrane currents in defined cell types of the anterolateral bed nucleus of the stria terminalis. J. Neurophysiol. 98, 638-656. doi: 10.1152/jn.00382.2007

Hazra, R., Guo, J. D., Ryan, S. J., Jasnow, A. M., Dabrowska, J., and Rainnie, D. G. (2011). A transcriptomic analysis of type I-III neurons in the bed nucleus of the stria terminalis. Mol. Cell. Neurosci. 46, 699-709. doi: 10.1016/j.mcn.2011.01.011

Herman, J. P., and Cullinan, W. E. (1997). Neurocircuitry of stress: central control of the hypothalamopituitary-adrenocortical axis Trends Neurosci. 20, 78-84. doi: 10.1016/S0166-2236(96)10069-2

Herman, J. P., Figueiredo, H., Mueller, N. K., Ulrich-Lai, Y., Ostrander, M. M., Choi, D. C., et al. (2003). Central mechanisms of stress integration: hierarchical circuitry controlling hypothalamo-pituitaryadrenocortical responsiveness. Front. Neuroendocrinol. 24 
151-180. doi: 10.1016/j.yfrne. 2003.07.001

Herman, J. P., Prewitt, C. M., and Cullinan, W. E. (1996). Neuronal circuit regulation of the hypothalamo-pituitaryadrenocortical stress axis. Crit. Rev. Neurobiol. 10, 371-394. doi: 10.1615/CritRevNeurobiol.v10.i34.50

Herman, J. P., Tasker, J. G., Ziegler, D. R., and Cullinan, W. E. (2002). Local circuit regulation of paraventricular nucleus stress integration: glutamate-GABA connections. Pharmacol. Biochem. Behav. 71, 457-468. doi: 10.1016/S00913057(01)00681-5

Hermes, M. L., Coderre, E. M., Buijs, R. M., and Renaud, L. P. (1996). GABA and glutamate mediate rapid neurotransmission from suprachiasmatic nucleus to hypothalamic paraventricular nucleus in rat. J. Physiol. 496(Pt 3), 749-757.

Herzog, E., Bellenchi, G. C., Gras, C., Bernard, V., Ravassard, P., Bedet, C., et al. (2001). The existence of a second vesicular glutamate transporter specifies subpopulations of glutamatergic neurons. J. Neurosci. 21, RC181.

Herzog, E., Gilchrist, J., Gras, C., Muzerelle, A., Ravassard, P., Giros, B., et al. (2004). Localization of VGLUT3, the vesicular glutamate transporter type 3 , in the rat brain. Neuroscience 123, 983-1002. doi: $\quad 10.1016 /$ j.neuroscience. 2003 . 10.039

Hoffman, N. W., Tasker, J. G., and Dudek, F. E. (1991). Immunohistochemical differentiation of electrophysiologically defined neuronal populations in the region of the rat hypothalamic paraventricular nucleus. J. Comp. Neurol. 307, 405-416. doi: $10.1002 /$ cne. 903070306

Hrabovszky, E., and Liposits, Z. (2008). Novel aspects of glutamatergic signalling in the neuroendocrine system. J. Neuroendocrinol. 20, 743-751. doi: 10.1111/j.1365-2826. 2008.01719.x

Hrabovszky, E., Wittmann, G., Turi, G. F., Liposits, Z., and Fekete, C. (2005). Hypophysiotropic thyrotropin-releasing hormone and corticotropin-releasing hormone neurons of the rat contain vesicular glutamate transporter-2. Endocrinology 146, 341-347. doi: 10.1210/en.2004-0856

Ishizuka, Y., Abe, H., Tanoue, A., Kannan, H., and Ishida, Y. (2010). Involvement of vasopressin $\mathrm{V} 1 \mathrm{~b}$ receptor in anti-anxiety action of SSRI and SNRI in mice.
Neurosci. Res. 66, 233-237. doi: 10.1016/j.neures.2009.11.004

Janitzky, K., Stork, O., Lux, A., Yanagawa, Y., Schwegler, H., and Linke, R. (2009). Behavioral effects and pattern of brain c-fos mRNA induced by 2,5-dihydro-2,4,5trimethylthiazoline, a component of fox feces odor in GAD67-GFP knock-in C57BL/6 mice. Behav. Brain Res. 202, 218-224. doi: 10.1016/j.bbr.2009.03.038

Jennings, J. H., Sparta, D. R., Stamatakis, A. M., Ung, R. L., Pleil, K. E., Kash, T. L., et al. (2013). Distinct extended amygdala circuits for divergent motivational states. Nature 496, 224-228. doi: 10.1038/nature12041

Kim, S. J., Park, S. H., Choi, S. H., Moon, B. H., Lee, K. J., Kang, S. W., et al. (2006). Effects of repeated tianeptine treatment on CRF mRNA expression in non-stressed and chronic mild stress-exposed rats. Neuropharmacology 50, 824-833. doi: $\quad 10.1016 /$ j.neuropharm.2005. 12.003

Kits, K. S., and Mansvelder, H. D. (2000). Regulation of exocytosis in neuroendocrine cells: spatial organization of channels and vesicles, stimulus-secretion coupling, calcium buffers and modulation. Brain Res. Brain Res. Rev. 33, 78-94. doi: 10.1016/S0165-0173(00)00023-0

Koob, G. F. (2010). The role of CRF and CRF-related peptides in the dark side of addiction. Brain Res. 1314, 3-14. doi: 10.1016/j.brainres.2009.11.008

Kovacs, K. J., and Sawchenko, P.E. (1993). Mediation of osmoregulatory influences on neuroendocrine corticotropin-releasing factor expression by the ventral lamina terminalis. Proc. Natl. Acad. Sci. U.S.A. 90, 7681-7685. doi: 10.1073/pnas.90.16.7681

Kudo, T., Uchigashima, M., Miyazaki, T., Konno, K., Yamasaki, M., Yanagawa, Y., et al. (2012). Three types of neurochemical projection from the bed nucleus of the stria terminalis to the ventral tegmental area in adult mice. J. Neurosci. 32, 18035-18046. doi: 10.1523/JNEUROSCI.4057-12.2012

Lee, H. J., Macbeth, A. H., Pagani, J. H., and Young, W. S. 3rd. (2009). Oxytocin: the great facilitator of life. Prog. Neurobiol. 88, 127-151.

Lee, Y., and Davis, M. (1997). Role of the hippocampus, the bed nucleus of the stria terminalis, and the amygdala in the excitatory effect of corticotropin-releasing hormone on the acoustic startle reflex. J. Neurosci. 17, 6434-6446.
Liang, K. C., Chen, H. C., and Chen, D. Y. (2001). Posttraining infusion of norepinephrine and corticotropin releasing factor into the bed nucleus of the stria terminalis enhanced retention in an inhibitory avoidance task. Chin. J. Physiol. 44, 33-43.

Lightman, S. L. (1993). Differential regulation of neurohypophysial peptides in the paraventricular nucleus. Regul. Pept. 45, 155-158. doi: 10.1016/0167-0115(93)90199-I

Lin, W., Mckinney, K., Liu, L., Lakhlani, S., and Jennes, L. (2003). Distribution of vesicular glutamate transporter-2 messenger ribonucleic Acid and protein in the septum-hypothalamus of the rat. Endocrinology 144, 662-670. doi: 10.1210/en.2002-220908

Liu, J., Yu, B., Neugebauer, V., Grigoriadis, D. E., Rivier, J., Vale, W. W., et al. (2004). Corticotropinreleasing factor and Urocortin I modulate excitatory glutamatergic synaptic transmission. J. Neurosci. 24, 4020-4029. doi: 10.1523/JNEUROSCI.5531-03.2004

Lolait, S. J., Stewart, L. Q., Jessop, D. S., Young, W. S. 3rd., and O'carroll, A. M. (2007). The hypothalamicpituitary-adrenal axis response to stress in mice lacking functional vasopressin $\mathrm{V} 1 \mathrm{~b}$ receptors. Endocrinology 148, 849-856. doi: 10.1210/en.2006-1309

Lowry, C. A., and Moore, F. L. (2006). Regulation of behavioral responses by corticotropin-releasing factor. Gen. Comp. Endocrinol. 146, 19-27. doi: 10.1016/j.ygcen.2005.12.006

Luther, J. A., and Tasker, J. G. (2000). Voltage-gated currents distinguish parvocellular from magnocellular neurones in the rat hypothalamic paraventricular nucleus. J. Physiol. 523(Pt 1), 193-209. doi: 10.1111/j. 1469-7793.2000.t01-1-00193.x

Ma, X. M., Levy, A., and Lightman, S. L. (1997). Rapid changes in heteronuclear RNA for corticotrophinreleasing hormone and arginine vasopressin in response to acute stress. J. Endocrinol. 152, 81-89. doi: 10.1677/joe.0.1520081

Martin, E. I., Ressler, K. J., Jasnow, A. M., Dabrowska, J., Hazra, R., Rainnie, D. G., et al. (2010). A novel transgenic mouse for genetargeting within cells that express corticotropin-releasing factor. Biol. Psychiatry 67, 1212-1216. doi: 10.1016/j.biopsych.2010.01.026

Mccarthy, M. M., Mcdonald, C. H., Brooks, P. J., and Goldman, D. (1996). An anxiolytic action of oxytocin is enhanced by estrogen in the mouse. Physiol. Behav.
60, 1209-1215. doi: 10.1016/S00319384(96)00212-0

Merchenthaler, I. (1993). Induction of enkephalin in tuberoinfundibular dopaminergic neurons during lactation. Endocrinology 133, 2645-2651. doi: 10.1210/en.133.6.2645

Miklos, I. H., and Kovacs, K. J. (2002). GABAergic innervation of corticotropin-releasing hormone $(\mathrm{CRH})$-secreting parvocellular neurons and its plasticity as demonstrated by quantitative immunoelectron microscopy. Neuroscience 113, 581-592. doi: 10.1016/S0306-4522(02)00147-1

Morin, S. M., Ling, N., Liu, X. J., Kahl, S. D., and Gehlert, D. R. (1999). Differential distribution of urocortin- and corticotropin-releasing factor-like immunoreactivities in the rat brain. Neuroscience 92, 281-291. doi: 10.1016/S0306-4522(98)00732-5

Nair, H. P., and Young, L. J. (2006). Vasopressin and pair-bond formation: genes to brain to behavior. Physiology (Bethesda) 21, 146-152. doi: 10.1152/physiol.00049.2005

Neumann, I. D. (2007). Stimuli and consequences of dendritic release of oxytocin within the brain. Biochem. Soc. Trans. 35, 1252-1257. doi: 10.1042/BST0351252

Neumann, I. D. Kromer, S. A. Toschi, N., and Ebner, K. (2000). Brain oxytocin inhibits the (re)activity of the hypothalamo-pituitary-adrenal axis in male rats: involvement of hypothalamic and limbic brain regions. Regul. Pept. 96, 31-38. doi: 10.1016/S0167-0115(00)00197-X

Nijsen, M. J., Croiset, G., Diamant, M., De Wied, D., and Wiegant, V. M. (2001). CRH signalling in the bed nucleus of the stria terminalis is involved in stress-induced cardiac vagal activation in conscious rats. Neuropsychopharmacology 24, 1-10. doi: 10.1016/S0893133X(00)00167-6

Orozco-Cabal, L., Pollandt, S., Liu, J., Shinnick-Gallagher, P., and Gallagher, J. P. (2006). Regulation of synaptic transmission by CRF receptors. Rev. Neurosci. 17, 279-307. doi: 10.1515/REVNEURO. 2006.17.3.279

Pompolo, S., Scott, C. J., and Clarke, I. J. (2002). Selective regulation of glutamic decarboxylase isoform 65 , but not isoform 67 , in the bed nucleus of the stria terminalis and the preoptic area of the ewe brain across the estrous cycle. Endocrinology 143, 544-550. doi: 10.1210/en.143.2.544

Rainnie, D. G., Bergeron, R., Sajdyk, T. J., Patil, M., Gehlert, D. R., and Shekhar, A. (2004). Corticotrophin 
releasing factor-induced synaptic plasticity in the amygdala translates stress into emotional disorders. J. Neurosci. 24, 3471-3479. doi: 10.1523/JNEURO SCI.5740-03.2004

Rainnie, D. G., Hazra, R., Dabrowska, J., Guo, J. D., Li, C. C., DeWitt, S. E. (2013). Distribution and functional expression of Kv4 family a subunits and associated KChIP $\beta$ subunits in the bed nucleus of the stria terminalis. J. Comp. Neurol. (in press).

Ring, R. H. (2005). The central vasopressinergic system: examining the opportunities for psychiatric drug development. Curr. Pharm. Des. 11, 205-225. doi: 10.2174/1381612053382241

Rivier, C., and Vale, W. (1983). Modulation of stress-induced ACTH release by corticotropinreleasing factor, catecholamines and vasopressin. Nature 305, 325-327. doi: $10.1038 / 305325 \mathrm{a} 0$

Roland, B. L., and Sawchenko, P. E. (1993). Local origins of some GABAergic projections to the paraventricular and supraoptic nuclei of the hypothalamus in the rat. J. Comp. Neurol. 332, 123-143. doi: 10.1002/cne.903320109

Roper, J., O'Carroll, A. M., Young, W. 3rd., and Lolait, S. (2011). The vasopressin Avpr 1b receptor: molecular and pharmacological studies. Stress $14,98-115$.

Sahuque, L. L., Kullberg, E. F., Mcgeehan, A. J., Kinder, J. R., Hicks, M. P., Blanton, M. G., et al. (2006). Anxiogenic and aversive effects of corticotropin-releasing factor (CRF) in the bed nucleus of the stria terminalis in the rat: role of CRF receptor subtypes. Psychopharmacology (Berl) 186, 122-132. doi: 10.1007/s00213-0060362-y

Sakanaka, M., Shibasaki, T., and Lederis, K. (1986). Distribution and efferent projections of corticotropin-releasing factorlike immunoreactivity in the rat amygdaloid complex. Brain Res. 382, 213-238. doi: 10.1016/00068993(86)91332-6

Salome, N., Stemmelin, J., Cohen, C., and Griebel, G. (2006). Differential roles of amygdaloid nuclei in the anxiolytic- and antidepressantlike effects of the V1b receptor antagonist, SSR149415, in rats. Psychopharmacology (Berl) 187,
237-244. doi: 10.1007/s00213-0060424-1

Sawchenko, P. E., Arias, C. A., and Mortrud, M. T. (1993). Local tetrodotoxin blocks chronic stress effects on corticotropinreleasing factor and vasopressin messenger ribonucleic acids in hypophysiotropic neurons. J. Neuroendocrinol. 5, 341-348. doi: $10.1111 / j .1365-2826.1993 . t b 00$ 493.x

Sawchenko, P. E., Swanson, L. W., and Vale, W. W. (1984a). Co-expression of corticotropinreleasing factor and vasopressin immunoreactivity in parvocellular neurosecretory neurons of the adrenalectomized rat. Proc. Natl. Acad. Sci. U.S.A. 81, 1883-1887. doi: 10.1073/pnas.81.6.1883

Sawchenko, P. E., Swanson, L. W., and Vale, W. W. (1984b). Corticotropinreleasing factor: co-expression within distinct subsets of oxytocin-, vasopressin-, and neurotensinimmunoreactive neurons in the hypothalamus of the male rat. J. Neurosci. 4, 1118-1129.

Silverman, A. J., Hou-Yu, A., and Chen, W. P. (1989). Corticotropin-releasing factor synapses within the paraventricular nucleus of the hypothalamus. Neuroendocrinology 49, 291-299. doi: $10.1159 / 000125131$

Singru, P. S., Wittmann, G., Farkas, E., Zseli, G., Fekete, C., and Lechan, R. M. (2012). Refeeding-activated glutamatergic neurons in the hypothalamic paraventricular nucleus (PVN) mediate effects of melanocortin signaling in the nucleus tractus solitarius (NTS). Endocrinology 153, 3804-3814. doi: 10.1210/en.2012-1235

Snyder, K., Wang, W. W., Han, R., Mcfadden, K., and Valentino, R. J. (2012). Corticotropin-releasing factor in the norepinephrine nucleus, locus coeruleus, facilitates behavioral flexibility. Neuropsychopharmacology 37, 520-530. doi: 10.1038/npp.2011. 218

Sterrenburg, L., Gaszner, B., Boerrigter, J., Santbergen, L., Bramini, M., Roubos, E. W., et al. (2012). Sex-dependent and differential responses to acute restraint stress of corticotropin-releasing factorproducing neurons in the rat paraventricular nucleus, central amygdala, and bed nucleus of the stria terminalis. J. Neurosci. Res. 90 , 179-192. doi: 10.1002/jnr.22737

Sun, N., and Cassell, M. D. (1993). Intrinsic GABAergic neurons in the rat central extended amygdala. J. Comp. Neurol. 330, 381-404. doi: 10.1002/cne. 903300308

Swanson, L. W., Sawchenko, P. E., Rivier, J., and Vale, W. W. (1983). Organization of ovine corticotropin-releasing factor immunoreactive cells and fibers in the rat brain: an immunohistochemical study. Neuroendocrinology 36, 165-186. doi: 10.1159/00012 3454

Takamori, S., Rhee, J. S., Rosenmund, C., and Jahn, R. (2000). Identification of a vesicular glutamate transporter that defines a glutamatergic phenotype in neurons. Nature 407, 189-194. doi: $10.1038 / 35025070$

Tasker, J. G., and Dudek, F. E. (1991). Electrophysiological properties of neurones in the region of the paraventricular nucleus in slices of rat hypothalamus. J. Physiol. 434, 271-293.

Vale, W., Spiess, J., Rivier, C., and Rivier, J. (1981). Characterization of a 41-residue ovine hypothalamic peptide that stimulates secretion of corticotropin and betaendorphin. Science 213, 1394-1397. doi: $10.1126 /$ science. 6267699

Valentino, R. J., Foote, S. L., and Aston-Jones, G. (1983). Corticotropin-releasing factor activates noradrenergic neurons of the locus coeruleus. Brain Res. 270, 363-367. doi: 10.1016/0006-8993 (83)90615-7

Valentino, R. J., Lucki, I., and Van Bockstaele, E. (2010). Corticotropin-releasing factor in the dorsal raphe nucleus: Linking stress coping and addiction. Brain Res. 1314, 29-37. doi: 10.1016/j. brainres.2009.09.100

Veenema, A. H., and Neumann, I. D. (2008). Central vasopressin and oxytocin release: regulation of complex social behaviours. Prog. Brain Res. 170, 261-276. doi: 10.1016/S0079-6123(08)00422-6

Walker, D. L., Miles, L. A., and Davis, M. (2009). Selective participation of the bed nucleus of the stria terminalis and CRF in sustained anxiety-like vs. phasic fear-like responses. Prog.
Neuropsychopharmacol. Biol. Psychiatry 33, 1291-1308. doi: 10.1016/j.pnpbp.2009.06.022

Whitnall, M. H., and Gainer, H. (1988). Major pro-vasopressin-expressing and pro-vasopressin-deficient subpopulations of corticotropinreleasing hormone neurons in normal rats. Differential distributions within the paraventricular nucleus. Neuroendocrinology 47, 176-180. doi: 10.1159/000124910

Zhu, W., Umegaki, H., Suzuki, Y., Miura, H., and Iguchi, A. (2001). Involvement of the bed nucleus of the stria terminalis in hippocampal cholinergic system-mediated activation of the hypothalamopituitary-adrenocortical axis in rats. Brain Res. 916, 101-106. doi: 10.1016/S0006-8993(01)02871-2

Ziegler, D. R., Cullinan, W. E., and Herman, J. P. (2002). Distribution of vesicular glutamate transporter mRNA in rat hypothalamus. J. Comp. Neurol. 448, 217-229. doi: $10.1002 /$ cne. 10257

Conflict of Interest Statement: The authors declare that the research was conducted in the absence of any commercial or financial relationships that could be construed as a potential conflict of interest.

Received: 23 May 2013; accepted: 12 August 2013; published online: 30 August 2013.

Citation: Dabrowska J, Hazra R, Guo J-D, DeWitt $S$ and Rainnie DG (2013) Central CRF neurons are not created equal: phenotypic differences in CRF-containing neurons of the rat paraventricular hypothalamus and the bed nucleus of the stria terminalis. Front. Neurosci. 7:156. doi: 10.3389/fnins. 2013.00156

This article was submitted to Neuroendocrine Science, a section of the journal Frontiers in Neuroscience. Copyright (C) 2013 Dabrowska, Hazra, Guo, DeWitt and Rainnie. This is an open-access article distributed under the terms of the Creative Commons Attribution License (CCBY). The use, distribution or reproduction in other forums is permitted, provided the original author(s) or licensor are credited and that the original publication in this journal is cited, in accordance with accepted academic practice. No use, distribution or reproduction is permitted which does not comply with these terms. 